\title{
Contrasting patterns of microbial dominance in the Arabidopsis thaliana phyllosphere
}

\author{
Derek S. Lundberg', Roger de Pedro Jové* ${ }^{*}$, , Pratchaya Pramoj Na Ayutthaya ${ }^{*}$, Talia L. \\ Karasov ${ }^{1,3}$, Or Shalev', Karin Poersch ${ }^{1,4}$, Wei Ding', Anita Bollmann-Giolai', Ilja Bezrukov', \\ Detlef Weigel ${ }^{1 \dagger}$
}

'Department of Molecular Biology, Max Planck Institute for Developmental Biology, 72076 Tübingen, Germany

2Present address: Centre for Research in Agricultural Genomics, 08193 Barcelona, Spain

${ }^{3}$ Present address: School of Biological Sciences, University of Utah, 84 I I 2 Salt Lake City, USA

${ }^{4}$ Present address: University of Freiburg, 79085 Freiburg im Breisgau, Germany

${ }^{5}$ Department of Evolutionary Biology and Environmental Studies, University of Zürich, 8057

Zürich, Switzerland

*These authors contributed equally.

†Corresponding author weigel@tue.mpg.de (D.W.)

\section{Abstract}

Pseudomonas and Sphingomonas are among the most abundant bacterial genera in the phyllosphere of wild Arabidopsis thaliana. Relative to Pseudomonas, the ecology of Sphingomonas and its interaction with plants remains elusive, despite its global ubiquity and known representatives of plant-beneficial strains. We analyzed the genomic features of over 400 endophytic Sphingomonas isolates collected from $A$. thaliana and neighboring plants, revealing high intergenomic diversity compared to much more homogenous Pseudomonas populations on the same plants. Variation in plasmid complement and additional genomic features suggest high adaptability, and the widespread presence of protein secretion systems hints at frequent biotic interactions. While some of the isolates showed plant-protective properties, this was a rare trait. To begin to understand the bacterial populations at the investigated $A$. thaliana sites and the alternate hosts of these strains when $A$. thaliana becomes limiting, we employed amplicon sequencing and a novel bulk-culturing metagenomics approach on $A$. thaliana and neighboring plants, both in spring when $A$. thaliana was flowering and in late summer before the emergence of the $A$. thaliana winter cohort. Our data reveal that Sphingomonas and Pseudomonas strains from $A$. thaliana not only survive, but also thrive on other diverse local plant hosts, suggesting that leaf-to-leaf transmission from these biotic reservoirs may be a major source of microbes to the next generation. 


\section{Introduction}

Most ecosystems, including host-associated microbiomes, are composed of a handful of common species and a wide assortment of rarer species $(I, 2)$. Perhaps unsurprisingly, common species are frequently implicated in direct interactions with the host and other microbes. For example in the human gut, the genera Bacteroides or Prevotella, which often occupy $20 \%$ or more of the entire community (3), both modulate the host immune system and are particularly successful competitors of other microbes (4). Similarly, on and inside plant leaves, the Proteobacterial genera Sphingomonas and Pseudomonas are among the most common bacterial taxa, not only on the model plant Arabidopsis thaliana (5-9), but also on many other species across continents (10-17).

Pseudomonas-leaf interactions are well studied (12, /8-20), largely due to interest in important plant pathogens in the genus (12). Sphingomonas-leaf interactions, however, are not nearly as well-understood at a genetic level or population level, despite their ubiquity on plant leaves and increasing reports of plant beneficial members (2I-23). Sphingomonas derives its name from its membrane-bound sphingolipids (24), common structural and signalling molecules in eukaryotes that are found in few bacterial taxa $(3,25)$. Curiously, these taxa include the previously mentioned Bacteroides and Prevotella of the gut, whose sphingolipids interact with the mammalian host and even influence host nutrition $(3,26)$. Whether Sphingomonas sphingolipids also interact with plants remains unknown (25). Sphingomonas also associate with plant roots (27) and seeds $(2 I)$ and are common in soil and freshwater (28) among other habitats. Some strains can improve plant growth and abiotic stress tolerance in contaminated soils (29), and various others can promote plant growth through the production of growth regulators (30). Sphingomonas strains affect the abundances of other microbes $(5,21,31,32)$, and some protect against pathogenic bacteria $(2 l, 33)$ or fungi $(22)$.

To relate leaf-associated Sphingomonas colonization and ecology, we used more familiar patterns of Pseudomonas colonization as a benchmark. In our previous studies of microbes colonizing local $A$. thaliana in southwest (SW) Germany, Pseudomonas varied widely in bacterial load on individual plants, ranging from nearly absent to very high titres $(7,9,18)$. At the genomic level, I,524 cultured Pseudomonas isolates from local $A$. thaliana plants consisted primarily of a group of closely-related $P$. viridiflava (hereafter referred to as $P v$-ATUE5) that shared at least $99.9 \%$ nucleotide identity in their core genomes and the same diagnostic partial I6S rRNA gene sequence (18). Despite their similarity to each other, Pv-ATUE5 strains differed in pathogenicity in a gnotobiotic system, and phylogenetic analysis suggested that subgroups of Pv-ATUE5 diverged around 300,000 years ago, consistent with complex selective pressures that have not favored conquest by a single isolate (/8).

In this work, we sought to characterize local Sphingomonas populations at the strain level to ask if, like $P v$-ATUE5, a single lineage rules the local $A$. thaliana bacterial community, and 
to determine general genetic features of plant-associated Sphingomonas. We also extended our survey onto neighboring plants of various species at the site and asked to what extent Sphingomonas and Pseudomonas strains common to $A$. thaliana are generalists, with selective pressures shaped by life on multiple host plants. This work reinforces the notion that individual Sphingmonas strains likely have broad host ranges and that they have genetic features equipping them for a multitude of biotic interactions, suggesting major roles not only in the assembly of leaf communities but also in the general plant perception of microbes.

\section{Results}

Sphingomonas colonizes leaves to similar levels as Pseudomonas, but more consistently

A previous dataset of sequenced metagenomes for 176 A. thaliana rosette samples ( 9 ) allowed us to calculate the bacterial load on the leaf as the ratio of bacterial to plant sequence counts in each sample. We used this ratio to scale, for every sample, the relative abundances of amplicon sequence variants (ASVs) of the V4 region of the I6S rRNA gene (hereafter rDNA) that had been prepared from the same DNA extraction, giving bacterial loads for each ASV. We first analyzed these ASVs at the genus level. Sphingomonas and Pseudomonas were approximately equal in abundance overall, and twice as abundant as the third most common genus (Pedobacter). However, Pseudomonas loads varied widely between samples, with a coefficient of variation (standard deviation / mean abundance) more than double that of Sphingomonas, which was among the most constant genera (Figure la). Impressively, the reliability of Sphingomonas colonization also applied to different Sphingomonas ASVs that independently colonized most plants (Figure Ib), suggesting that strains from each ASVs may occupy a different niche in the leaf rather than competing with each other to fill up a general "Sphingomonas niche" on a given plant. We named the most abundant Sphingomonas and Pseudomonas ASVs, whose average abundance was several fold higher than the next most abundant ASVs in each genus, SphASVI-V4 and PseASVI-V4, respectively.

\section{Major Sphingomonas and Pseudomonas ASVs are enriched endophytically}

We reanalysed a previous dataset of slightly longer rDNA sequences in the V3V4 region (18) that partitioned $A$. thaliana leaf epiphytes from endophytes using thorough surface sterilization, and located ASVs containing an exact match to the SphASVI-V4 and PseASVI-V4 described above. We found for each a single match to a highly abundant V3V4 ASV, and we refer to the longer V3V4 rDNA sequences henceforth as SphASVI and PseASVI. PseASVI uniquely matched the representative sequence previously used to define the $P V$-ATUE5 lineage (18). SphASVI was more abundant than PseASVI in both the epiphytic and endophytic fractions of the leaf, and both were well-represented in the endophytic compartment (Figure Ic), suggesting the capability to evade or tolerate the plant immune system and persist inside the 
leaf. SphASVI was in fact the most abundant single ASV in the dataset. The combination of numerical dominance, endophytic enrichment, and high consistency of colonization drove our interests to characterize genetic and ecological features of this ASV and local Sphingomonas more generally.

\section{Sphingomonas has a wider host range than Pseudomonas in the phyllosphere}

An abandoned train station in Eyach, Germany, supports a population of hundreds to thousands of $A$. thaliana plants, and has been a source of material for several recent plant-associated microbiome studies $(5,7,18,34)$. We collected $A$. thaliana and neighboring plants in spring, when most $A$. thaliana plants were green, mature, and flowering. We also collected plants in late summer when there were no living $A$. thaliana because all plants of the species had senesced and dried out by mid summer, and the next cohort had not yet germinated. We reasoned that by late summer, the springtime $A$. thaliana-associated microbial community must have either migrated to survive in other plant hosts or non-plant habitats, or died $(12,35,36)$, and thus at this later time point we could rule out that any isolates collected from other species or soil were direct migrants from $A$. thaliana hosts.

For each plant species, we pooled at least one entire leaf from at least 6 independent individuals per sample, collecting 7 independent samples per species. Although this pooling strategy that spanned many plants precluded analysis of variation between individual hosts, it maximized our ability to broadly survey the site (Supplementary Figure I). After bringing leaf samples back to the lab, we surface-sanitized them in 70\% ethanol for 45-60 seconds and macerated them in buffer with a mortar and pestle. We then mixed the fresh lysate with glycerol to make $-80^{\circ} \mathrm{C}$ freezer stocks that cryo-protected the live bacteria (Methods).

We first extracted metagenomic DNA directly from the frozen lysates using a custom bead-beating based protocol as previously described $(9,18)$, and prepared I6S rDNA amplicon libraries spanning the V3 and V4 regions (Methods) using peptide nucleic acids (PNAs) to reduce organelle amplification (37). The residual chloroplast sequences in each sample corresponded to the expected plant host species, confirming that we had correctly identified species for harvest (Supplementary Figure 2). We could not obtain sufficient bacterial reads from dandelion and thistle due to a natural mutation in their chloroplast sequences that made our PNAs ineffective (38), and I6S rDNA bacterial abundance data from these species are therefore absent due to an overabundance of organelle sequences. To contrast bacterial communities across the sampled plant hosts, we binned the ASVs into bacterial families, and clustered samples by their pairwise Bray-Curtis dissimilarity (Figure Id). This revealed substantial similarities in bacterial family membership between groups of samples, with clear plant clustering both by sampling season and also by some plant taxa, consistent with previous publications linking plant genotype and seasonal effects to bacterial community composition ( $/ 3$, 39). The family Pseudomonadaceae, of which $92.9 \%$ was the genus Pseudomonas, reached high relative abundances in $A$. thaliana, but also in some other hosts-particularly the other 
bioRxiv preprint doi: https://doi.org/10.1101/2021.04.06.438366; this version posted April 13, 2021. The copyright holder for this preprint (which was not certified by peer review) is the author/funder, who has granted bioRxiv a license to display the preprint in perpetuity. It is made available under aCC-BY 4.0 International license.

Lundberg et al.

Contrasting patterns of microbial dominance

Brassicaceae Draba verna and Cardamine hirsuta (Figure le). Sphingomonadaceae, of which $\mathbf{8 0 . 7 \%}$ corresponded to the genus Sphingomonas, was ubiquitous and abundant across all plant hosts (Figure Ie, Supplementary Figure 3). As on $A$. thaliana, PseASVI and SphASVI accounted for a substantial fraction of reads from Pseudomonas and Sphingomonas (44.7\% and 39.4\%, respectively) (Figure If, Ig).

a
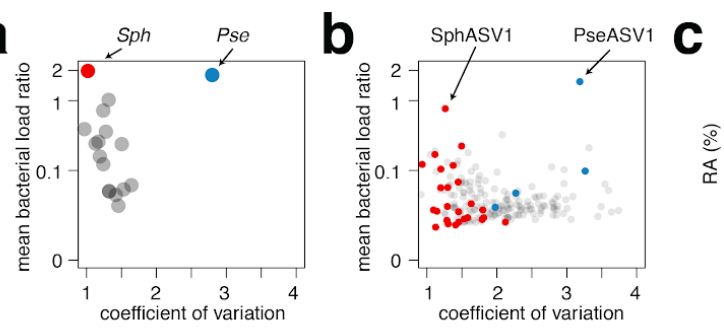

d
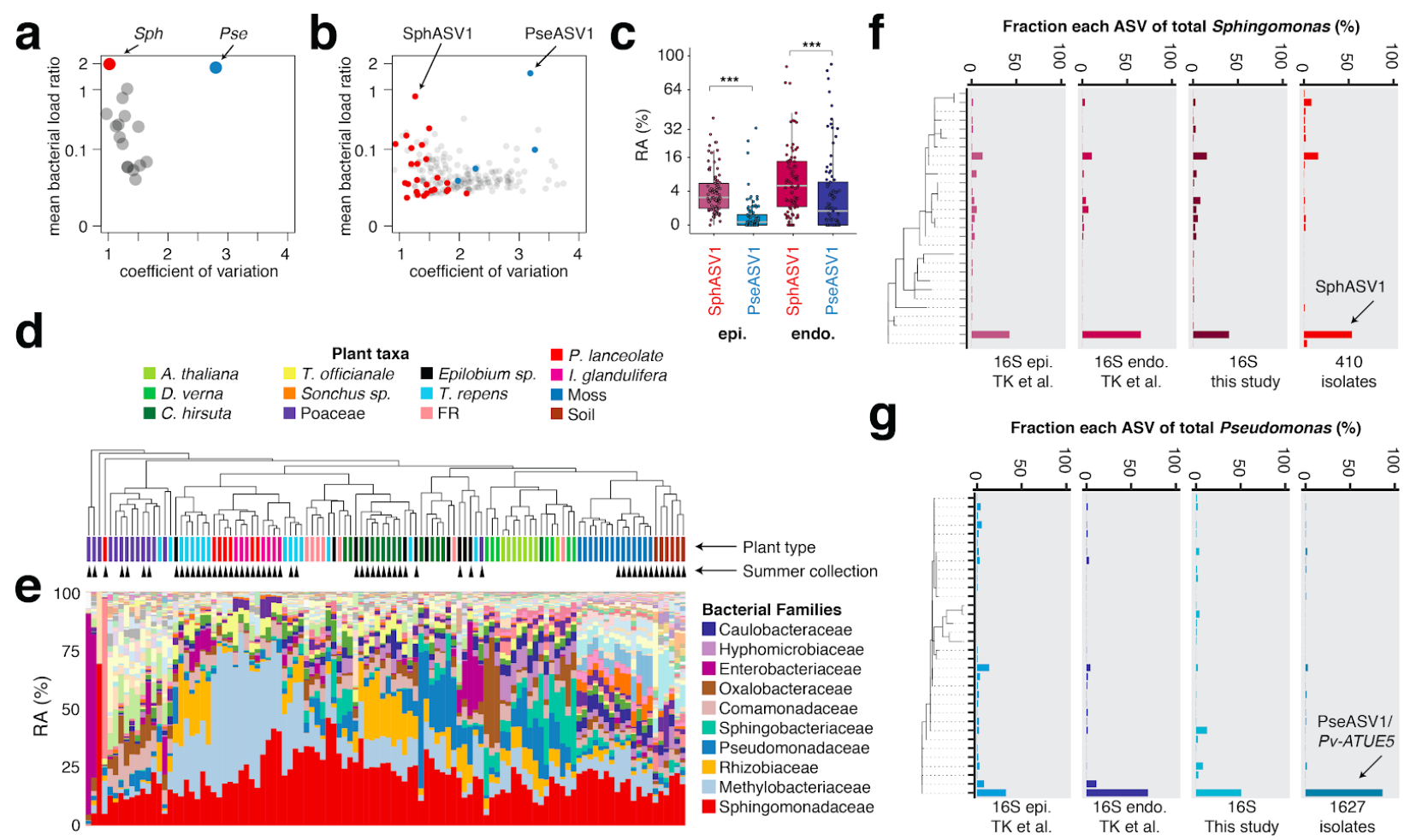

g

Figure I. Sphingomonas and Pseudomonas are abundant and culturable, but differ in consistency of colonization | a) Sphingomonas (red, S) has a similarly high bacterial load to Pseudomonas (blue, P) across I76 A. thaliana plants from (9), but among the lowest coefficients of variation (standard deviation / mean abundance) of other major genera (grey). b) Similar to (a), but showing the I6S rDNA sequences that make up the most abundant genera. Sphingomonas ASVs (including SphASVI) have on average low coefficients of variation, and Pseudomonas ASVs have on average higher coefficients of variation. c) The median relative abundance (RA) of SphASVI is higher than PseASVI both epiphytically (epi.) and endophytically (endo.) (*** $p<0.00$ I, FDR-adjusted Mann-Whitney U-test). d) Plant samples are clustered by the Bray-Curtis dissimilarity of the relative abundance of bacterial families. Summer collection indicated with black triangles. e) Stacked bars represent the relative abundances (RA) of bacterial families in the present study, with the key to the top 10 bacterial families at right. $\mathrm{f}$ ) Relative abundances of Sphingomonas ASVs detected epiphytically (epi.) and endophytically (endo.) in TK et al. ( /8), this study, and in 410 locally-cultured isolates from multiple plant species. SphASVI is indicated. g) Same as in $\mathbf{f}$, but for Pseudomonas, with 1,627 isolates combining 1,524 from (18) and 103 additional isolates from this study. PseASVI is indicated.

\section{Cultured bacterial populations resemble those on wild leaves}

Pseudomonas isolates from local $A$. thaliana populations, the majority of which were associated with the PseASVI $16 \mathrm{~S}$ rDNA sequence, have been previously characterized (18). To investigate Sphingomonas genome diversity across host species, and likewise to characterize the 
genomic features associated with highly abundant Sphingomonas groups, we cultured endophytic Sphingomonas from frozen plant lysates using both remaining $A$. thaliana lysates from (18) as well as lysates from the diverse plant hosts in the present study. We enriched for Sphingomonas using LB supplemented with $100 \mathrm{mg} / \mathrm{mL}$ streptomycin, an antibiotic to which most Sphingomonas is resistant due to a natural mutation in the $r p s L$ gene (40), and isolated 410 Sphingomonas colonies. Using LB supplemented with $100 \mathrm{mg} / \mathrm{mL}$ nitrofurantoin as previously described (18), we also isolated an additional 103 Pseudomonads. We generated draft genome assemblies with an average of 65 -fold genome coverage and BUSCO (4I) completeness of at least $85 \%$ (Methods). We first extracted from the assemblies the V3 and V4 regions of the I6S rDNA, allowing us to relate the genomes to our existing ASVs. Critically, for both Pseudomonas and Sphingomonas, we recovered isolates in relative abundances consistent with those from culture-independent surveys (Figure If, Ig), demonstrating that culturing did not introduce substantial biases in recovery rates, and that we had sequenced a sufficient number of isolates to capture broad patterns of diversity on leaves.

\section{Sphingomonas I6S rDNA sequence similarity belies high genomic diversity}

Previously we observed low genomic diversity among PseASVI/PV-ATUE5 strains isolated from $A$. thaliana (18). To similarly evaluate genomic diversity for an analogous set of Sphingomonas, we selected all the Sphingomonas isolates in our collection from $A$. thaliana that also had the SphASVI I6S rDNA sequence (I74 SphASVI out of 340 total $A$. thaliana isolates). We compared the genomes to each other using MASH (42), which decomposes genomes into $k$-mers and calculates a distance based on the fraction of shared $k$-mers. As an additional comparator, we also included a representative set of 99 diverse PseASVI/PV-ATUE5 genomes isolated from $A$. thaliana, comprising all 82 in a condensed tree of 165 strains from (/8) that were at least $0.1 \%$ different across the core genome, and an additional 17 strains from this study. We converted the MASH distances to a similarity score between 0 (least similar) and 100 (identical) (Methods). When PseASVI/Pv-ATUE5 genomes were compared to each other, all comparisons had MASH similarities > 95. However, the majority of pairwise comparisons between SphASVI-associated Sphingomonas genomes had similarities of 90 or less, indicating that the V3V4 region of the I6S rDNA sequence was a relatively poor predictor of genome similarity in Sphingomonas (Figure 2a, 2b). We extracted full-length 165 rDNA sequences from the genomes and clustered them into operational taxonomic units (OTUs) at $99.5 \%$ identity, which yielded no additional subgroups for PseASVI/Pv-ATUE5 strains, but partitioned SphASVI-associated strains into 6 subgroups (Figure 2a). Genomes within these subgroups were more similar, but pairwise MASH similarities within one such subgroup of 46 isolates still averaged less than 95, further confirming that 16S rDNA was less informative for local Sphingomonas than for local Pseudomonas (Figure 2b).

We initially suspected the relatively high overall genome diversity of SphASVI-associated isolates compared to $P v$-ATUE5 isolates might be due to high variation in the accessory 
bioRxiv preprint doi: https://doi.org/10.1101/2021.04.06.438366; this version posted April 13, 2021. The copyright holder for this preprint (which was not certified by peer review) is the author/funder, who has granted bioRxiv a license to display the preprint in perpetuity. It is made available under aCC-BY 4.0 International license.

\section{Lundberg et al.}

Contrasting patterns of microbial dominance
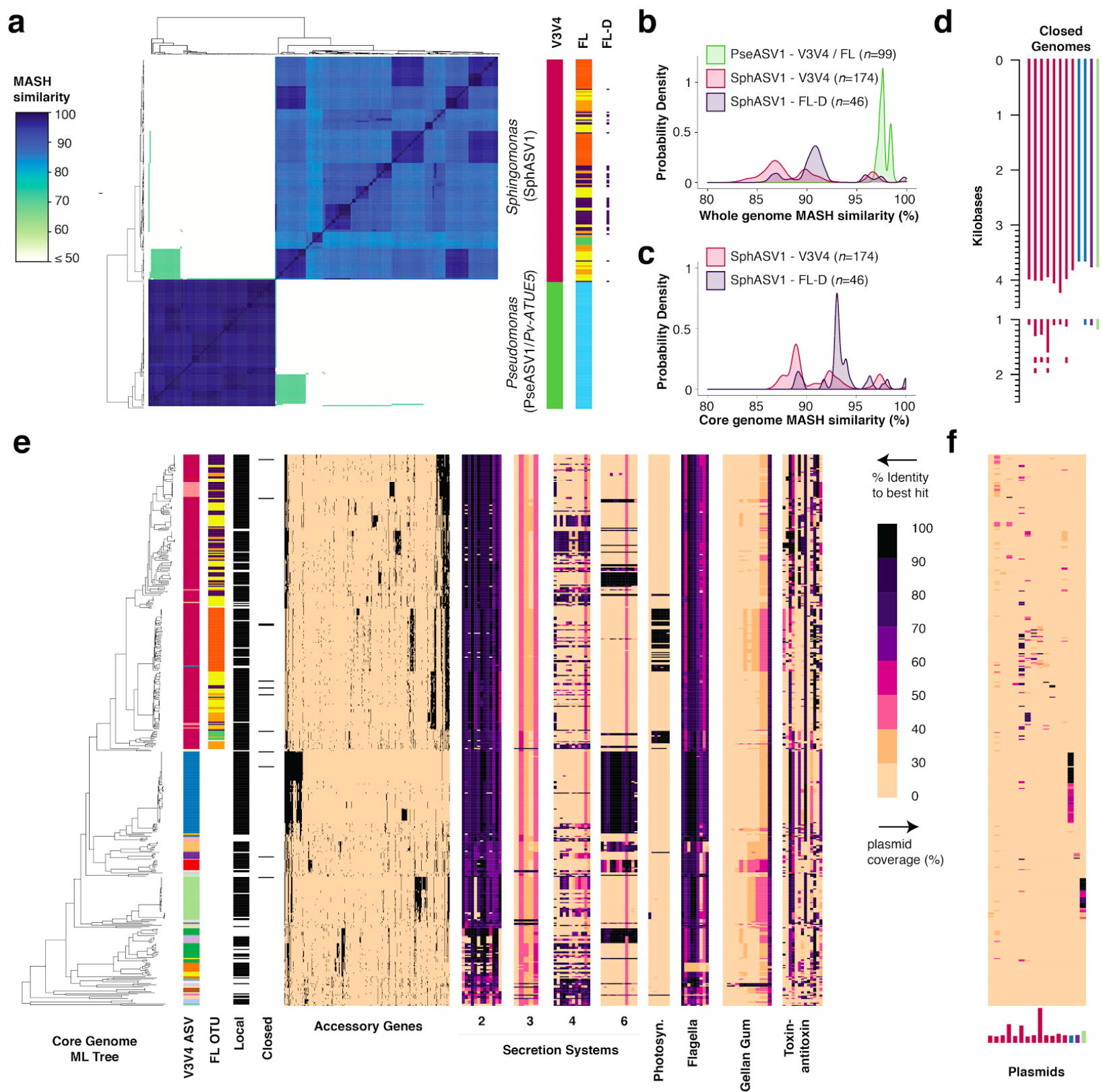

Figure 2. Sphingomonas I6S rDNA sequences belie high genomic diversity | a) Heatmap of MASH similarity between 99 Pseudomonas PseASVI/Pv-ATUE5 genomes and 174 Sphingomonas SphASVI genomes. Color bars to the right indicate which genomes contain the V3V4 I6S rDNA ASV used to define PseASVI and SphASVI ('V3V4') and which belong to different full length I6S rDNA OTU ('FL'). A diverse group of genomes sharing a full length OTU is also indicated (FL-D) b) Density plot showing the distribution of MASH similarities shown in the heatmap in (a), subset by bacterial genus and I6S rDNA grouping. V3V4, variable regions 3 and 4; FL, a full length OTU; FL-D, the group of highly diverse genomes sharing a full length OTU sequence as indicated in (a). c) similar to (b) but showing MASH similarity calculated only on an alignment of 274 core genes. d) Base map of the 12 closed genomes, colored by their V3V4 I6S group, showing plasmids to scale. e) Core genome maximum likelihood tree of 410 Sphingomonas isolates from this study and 70 from RefSeq based on 274 core genes, with genomic features indicated by aligned heatmaps. 'V3V4', color map of the different V3V4 ASV sequences associated with each genome (white if unknown); 'FL OTU', color map of the $99.5 \%$ identity OTUs associated with SphASVI and and closely-related ASVs; 'Local', 4I0 genomes sequenced and isolated in this study are indicated by black; 'Accessory Genes', presence absence matrix of all genes not used to compute the ML tree; 'Secretion Systems', 
BLAST results of each genome against genes of the type 2, 3, 4, and 6 secretion systems, with percent identities as indicated by the color legend. 'Photosyn', genes involved in anoxygenic photosynthesis; 'Flagella', genes involved in building an operating flagellum; 'Toxin-antitoxin', genes associated with toxin-antitoxin pairs. f) 'Plasmids', percent coverage of plasmid sequences from the closed genomes, with the relative size and ASV background of each plasmid indicated by the length and color of the bars.

genome-specifically the differential presence of plasmids. We noted that some publicly-available complete genomes of Sphingomonas contained several plasmids, and after closing 12 of our genomes with long-read sequencing (Methods), we detected a total of 16 plasmids with up to three per genome, comprising up to $14 \%$ of the total genome size (Figure 2d). We therefore recalculated genome similarities using 274 shared genes identified as the soft core genome of our Sphingomonas dataset after annotating open reading frames using Prokka (43), and using PanX (44) to identify genes present in at least $70 \%$ of genomes (Methods). We compared the aligned core genomes of SphASVI-associated isolates again using MASH (Figure 2c). SphASVI-associated core-genomes were more diverse than even whole genomes (which include accessory genes) of Pv-ATUE5. Thus, despite the pervasiveness of the SphASVII6S rDNA sequence in our dataset, we cannot currently extrapolate what this ASV sequence means at the level of genomic content.

\section{Sphingomonas genomes reveal adaptations for competitive life in the phyllosphere}

To explore relatedness of SphASVI-associated genomes, and how they compare with other Sphingomonas genomes from our collection, we calculated maximum-likelihood (ML) core genome phylogenies (44) from all 410 local Sphingomonas isolates (340 from $A$. thaliana and 70 from other local plant hosts), along with 70 sequence-related isolates from NCBI RefSeq (45) (Figure 2e). Gene presence or absence in the accessory genome appeared to correspond to divisions in the core genome tree. We compiled a short list of Sphingomonas genes that had a high likelihood, based on literature, to improve survival among competing bacteria, or to facilitate interaction with a plant host, and made a custom database of Sphingomonas protein sequences. We searched for these features in our genomes by aligning the assemblies using BLASTX (46). We considered matches with at least 30\% amino acid identity over at least $60 \%$ of the protein length as positive hits. While nearly all isolates haddiagnostic genes for the type 2 secretion system, and genes for the type 4 and type 6 secretion systems were common among some clades including those of SphASVI, only a handful of less abundant strains seemed to potentially have a type 3 secretion system (Figure 2e). Flagellar motility is common. A group of SphASVI genomes has a full suite of genes for anoxygenic photosynthesis, a fascinating feature that can supplement heterotrophic energy production and likely improves survival in well-illuminated and nutrient-poor conditions such as the phyllosphere (47-50). All genomes were rife with toxin-antitoxin systems, likely to stabilize plasmids or superintegrons $(5 /)$. Indeed, we found widespread evidence of plasmids in our draft genomes by using minimap2 (52) to search for alignments to the 16 circularized plasmid sequences from our 12 complete 
genomes (Figure 2d). Considering alignments covering at least $30 \%$ of the length of a plasmid as a positive hit, $250(60 \%)$ of our isolates showed signatures of one or more of these 16 plasmids (Figure 2f).

To increase confidence in the preceding gene searches in our draft genomes, we repeated the analysis comparing the 12 closed genomes to their draft genome counterparts. Both draft and complete versions of each genome clustered tightly in a ML tree, and showed essentially the same presence/absence patterns (Supplementary Figure 4), suggesting that draft genomes were sufficient for analysis of gene content at this level of detail.

\section{Some Sphingomonas attenuate Pseudomonas virulence in A. thaliana}

Besides reaching similarly high abundances in the same leaves (Figure la-b), both Sphingomonas and Pseudomonas grow on many similar substrates in vitro (33), suggesting potential niche overlap in the phyllosphere. Previous work revealed that certain strains of Sphingomonas, in particular S. melonis $\mathrm{Frl}$, can ameliorate symptoms in $A$. thaliana leaves caused by pathogenic Pseudomonas and Xanthomonas in a gnotobiotic system $(23,33,53)$, and more recently a strain of $S$. melonis was demonstrated to protect rice against seedling blight pathogen Burkholderia plantarii. We first sought to screen some of our local isolates for potential plant-protective activity against virulent PV-ATUE5 strains in a gnotobiotic 24-well plate agar system, as we used previously (/8).

We germinated an $A$. thaliana accession endemic to our field site, Eyl5-2, on $1 / 2$ strength MS media in the presence of each of 19 strains of local Sphingomonas that represented much of the diversity of our collection, as well as $S$. melonis Frl. Following 10 days of co-cultivation, we challenged the plants with Pseudomonas, either the virulent local $P$. viridiflava strain PV-ATUE5:p25c2 (18) or the model pathogen P. syringae (Pst) DC3000, and monitored plant health over the next 6 days by measuring green pixels (Methods). Generally, Pst DC3000 slowed plant growth compared to buffer control, while Pv-ATUE5:p25c2 killed plant tissues (Figure 3a-d). However, in both this experiment and in a replicate experiment, our Sphingomonas strain SphATUESI39HI33 and S. melonis Frl improved plant health in the presence of PV-ATUE5:p25c2 (Figure 3a-b, Supplementary Figure 5), with infected plants not dying, but instead growing slowly at a rate not different than plants treated with the less deadly Pst DC3000 (FDR-adjusted Mann-Whitney U-test, $p>0.05$ ).

Surprisingly, seedlings germinated in the presence of $S$. melonis $\mathrm{Frl}$ in these conditions, although green even after Pseudomonas infection, were consistently stunted compared to those germinated in buffer or those germinated with any other Sphingomonas, including the protective SphATUE:SI39HI 33 (Figure 3a, 3c). We also observed this stunting phenotype in the Col-0 accession (not shown) for which a protective effect of $S$. melonis Frl had been previously reported. Although the authors reported that the plant transcriptomic response to protective S. melonis $\mathrm{Frl}$ involved induction of a set of defense genes overlapping those induced by Pst DC3000 (53), they did not observe negative effects on plant growth due to $S$. melonis $(23,53)$. 
We suspected that our result might be due to differences in our gnotobiotic system. Because gnotobiotic systems are entirely different environments than what plants experience in nature, we also tested plant protection for plants grown on soil. We therefore set up a similar experiment in which 2-week old seedlings grown on potting soil were sprayed first with Sphingomonas and 4 days later challenged with Pseudomonas sprayed at high concentrations $\left(\right.$ O.D. $\left._{600}=1.0\right)$, using environmental conditions known to produce robust symptoms (54). At 5 days post infection (dpi), we observed well-reported Pst DC3000 symptoms on most plants including chlorotic leaves, stunted growth, and increased anthocyanin at the apical meristem (54). However Pv-ATUE5:p25c2, which was consistently deadly on agar plates, did not produce symptoms on soil-grown $A$. thaliana of a similar age (Methods) and had no clear effect on rosette size (Figure $3 \mathrm{e}$ ). Because some disease resistance responses break down at very high humidity (55), we reasoned that we might not see Pv-ATUE5:p25c2 symptoms on soil due to natural resistance mechanisms that are suppressed in the $\sim 100 \%$ relative humidity of the gnotobiotic system. We therefore also infected soil-grown plants of the immune-compromised A. thaliana mutant enhanced disease susceptibility I (edsI-I), which is defective for numerous defense responses mediated by salicylic acid (SA) $(56,57)$ and highly susceptible to Pst DC 3000 infection (58). We also observed no symptoms on eds I-I, with infected plants indistinguishable from those sprayed with boiled Pseudomonas control (Figure 3e). Pst DC3000, in contrast, induced strong disease symptoms on eds I-I. In the future, it will be important to extend these results to mutants defective in jasmonic acid (JA) signalling, which is more important than SA in defense against other isolates of $P$. viridiflava (59).

We did not observe a clear protective effect of any Sphingomonas strain against Pst DC3000 symptoms on soil (Figure 3f), and furthermore $S$. melonis Frl-treated plants grown on soil were not stunted. To confirm that Sphingomonas was still present on leaves at the end of the experiment, and if pathogen titres had been affected, we quantified bacterial communities in the leaves of 5 plants per condition at 5 dpi using hamPCR (60), a quantitative amplicon sequencing approach that derives bacterial load by relating abundance of I6S rDNA to a single-copy host gene). Encouragingly, we observed the expected Sphingomonas I6S rDNA sequences enriched in each endpoint sample (Figure 3g). Supporting a protective role for $S$. melonis FrI on soil, samples pre-treated with this strain supported less Pst DC3000 than those pre-treated with others, and this was true on both the EyI5-2 and eds/-I backgrounds, although the difference was only significant in eds I-I (Mann-Whitney U-test, $\mathrm{p}<0.05$ ). However, we found no robust support that any of the local isolates, including SphI39HI33 that was protective on agar, reduced pathogen titres for plants grown on soil. Consistent with the plant phenotypes, Pst DC3000, but not Pv-ATUE5.p25c2, grew to higher titres in edsI-I than in Ey I5-2 (Supplementary Figure 6). 
bioRxiv preprint doi: https://doi.org/10.1101/2021.04.06.438366; this version posted April 13, 2021. The copyright holder for this preprint (which was not certified by peer review) is the author/funder, who has granted bioRxiv a license to display the preprint in perpetuity. It is made available under aCC-BY 4.0 International license.

Lundberg et al.

Contrasting patterns of microbial dominance
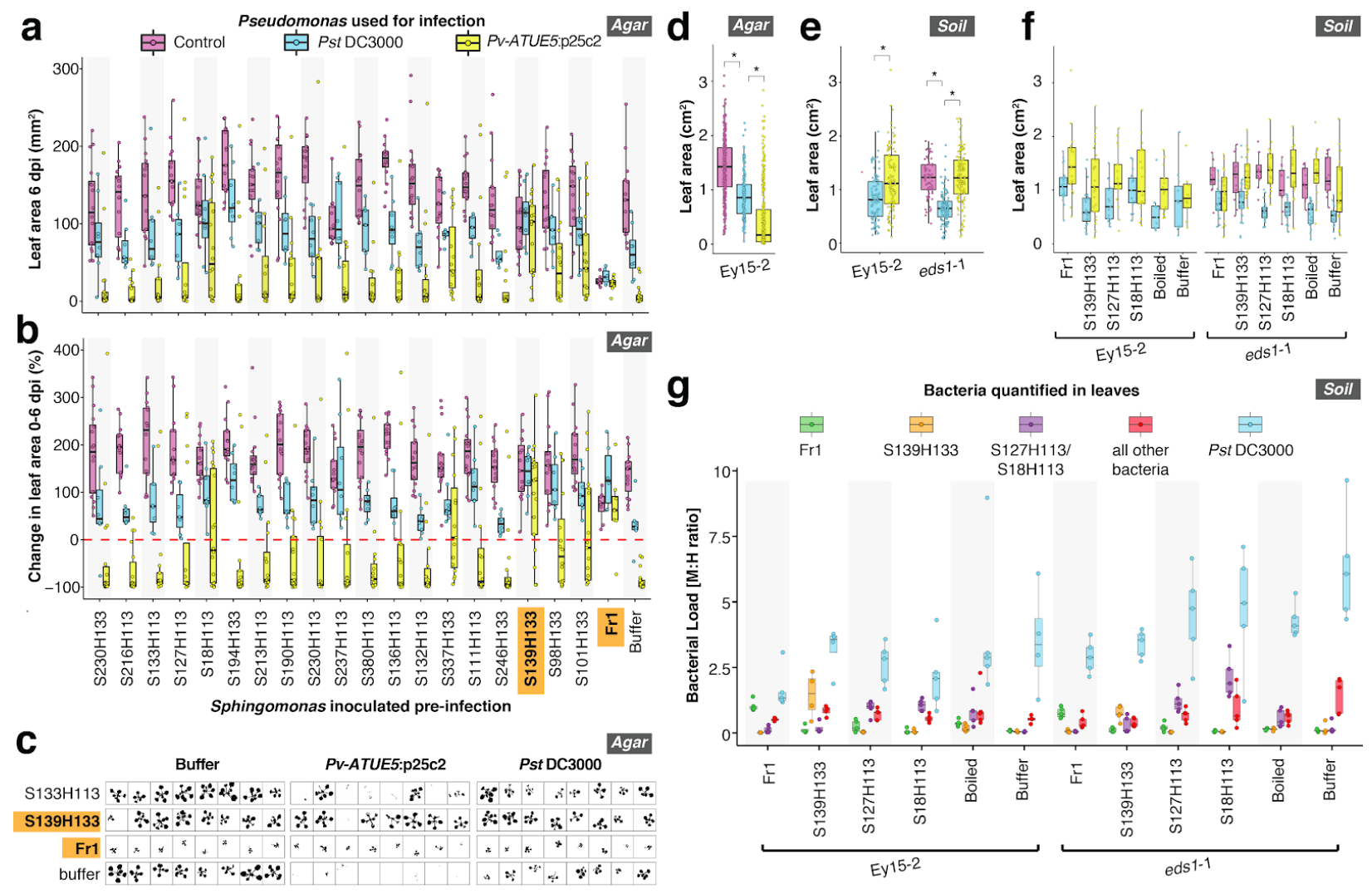

Figure 3. Some Sphingomonas offer protection against Pseudomonas | a-f) 19 local Sphingomonas isolates, S. melonis Frl (Frl), or buffer were used to pre-treat $A$. thaliana Eyl5-2 seeds germinating in 24-well agar plates. On day 10, seedlings were challenged with a buffer control, Pst DC3000, or PV-ATUE5:p25c2 and monitored for 6 days after infection ( $n \geq 6$ per condition). Orange-highlighted Sphingomonas insignificant difference between infected and buffer-treated plants (Mann-Whitney U-test with FDR adjustment, $p>0.05$ ) a) Absolute size of rosettes at $6 \mathrm{dpi}$. b) Percent change in rosette size between 0-6 dpi. c) Representative silhouettes at $6 \mathrm{dpi}$ of seedlings grown in 24-well plates. d) Rosette size by infection treatment, regardless of Sphingomonas pretreatment. $*=\mathrm{P}<0.00 \mathrm{I}$ (Mann-Whitney U-test with FDR adjustment). e-g) Three local Sphingomonas isolates, S. melonis Frl, or buffer was sprayed on 2-week old seedlings of Eyl5-2 or eds/-I, and 4 days later, live Pseudomonas, boiled Pseudomonas, or buffer was inoculated. e) Absolute sizes of rosettes for different Pseudomonas treatments, regardless of Sphingomonas treatment. $*=\mathrm{P}<0.00 \mathrm{I}$ (Mann-Whitney U-test with FDR adjustment). f) Same data as in (e), but split by Sphingomonas pre-treatment. g) Bacterial load ratio in plants infected with Pst DC3000 as determined by hamPCR. Note that the color legend represents bacteria quantified, not the bacteria used for treatment.

\section{Sphingomonas and Pseudomonas strains thrive on multiple plant species}

Sphingomonas and Pseudomonas are generalists, with no known exclusive hosts of any given strain (/2). As a first step towards determining the extent of generalization of strains across local plant species, we compared ASVs across plants. We observed that SphASVI was more abundant overall in the spring collection, but it was consistently detectable on most plant species in both seasons. Plant taxa colonized by SphASVI were also frequently colonized by multiple additional Sphingomonas ASVs to appreciable levels (Figure 4a). In contrast, PseASVI was relatively more abundant for $A$. thaliana, $C$. hirsuta and $D$. verna - all from the family 
Brassicaceae - and less abundant, though still present, on other taxa (Figure 4b). PseASVI was especially enriched in the spring, which matches our previous finding of more PV-ATUE5 isolates from spring vs. winter collected $A$. thaliana (18). The presence of an ASV across plant species is not necessarily an indication that bacterial strains are shared across plants. To test for strain sharing, we compared genome similarity for all PseASVI and SphASVI genomes we isolated from $A$. thaliana and four other plant species chosen for individual colony isolation: T. officinale, T. repens, C. hirsuta, and I. glandulifera (Figure 4c, 4d). These plants were chosen for isolates due to robust cultivation of both Pseudomonas and Sphingomonas from the same glycerol stocks for these species.

While 29 out of the 86 SphASVI isolates from the 2018 harvest shared at least $99.9 \%$ ANI with at least one other isolate, with only one exception these highest-similarity isolates came from the same lysate pool, meaning they could be clonal descendants from the same plant and might not represent a migration event to a new plant. To avoid potential intra-plant clones, we recalculated all pairwise genome similarities between the SphASVI isolates, ignoring those comparisons within the same lysate pool. We compared similarity within $A$. thaliana isolates (intra-host isolate similarity) and between $A$. thaliana isolates and those from any other plant species (inter-host isolate similarity). A higher intra-host similarity would be evidence of host-specificity, possibly due to unique selective forces within $A$. thaliana, or easier migration between individuals (for example facilitated by insects). We found that the distribution of intra-host ANI values closely matched that of inter-host isolate ANI values (Figure 4e), with the intra-host ANI being only marginally higher $(0.9 \%$, Mann-Whitney $U$ test, $p<0.00 \mathrm{I})$.

PseASVI-associated genomes were more similar to each other than SphASVI-associated genomes (Figure 2a). Every isolate shared at least $97.5 \%$ ANI with at least one isolate from a different plant species, and 47 of the 50 isolates shared at least $99.9 \%$ ANI with at least one other isolate (Figure 4d) but as with SphASVI, these highest-similarity isolates tended to come from the same plant pool. Three groups of highest-similarity isolates were shared across different plant pools, different species, and even different seasons (Figure 4d). This is consistent with our previous observation that PV-ATUE5 strains are common and persistent (/8), and further demonstrates that other local plant species host these strains. As with SphASVI isolates, the intra-host ANI values followed a similar distribution to inter-host ANI values, with intra-host isolate ANI values marginally higher $(0.4 \%$, Mann-Whitney U-test, $\mathrm{P}<0.00 \mathrm{I}$, Figure 4f). 
bioRxiv preprint doi: https://doi.org/10.1101/2021.04.06.438366; this version posted April 13, 2021. The copyright holder for this preprint (which

was not certified by peer review) is the author/funder, who has granted bioRxiv a license to display the preprint in perpetuity. It is made available under aCC-BY 4.0 International license.

Lundberg et al. Contrasting patterns of microbial dominance

a
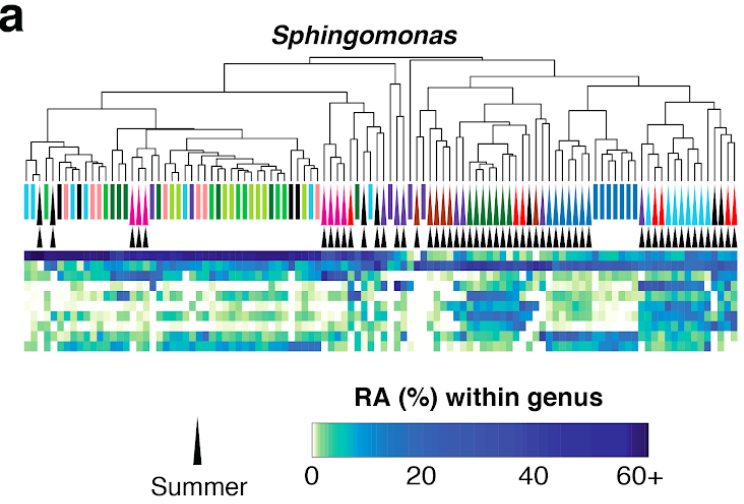

b

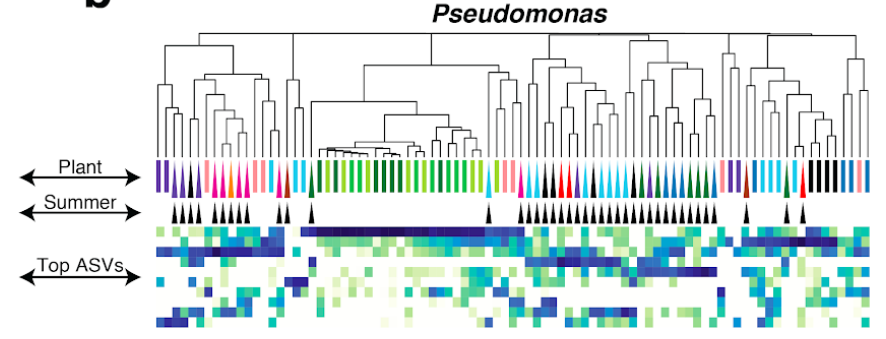

Plant taxa

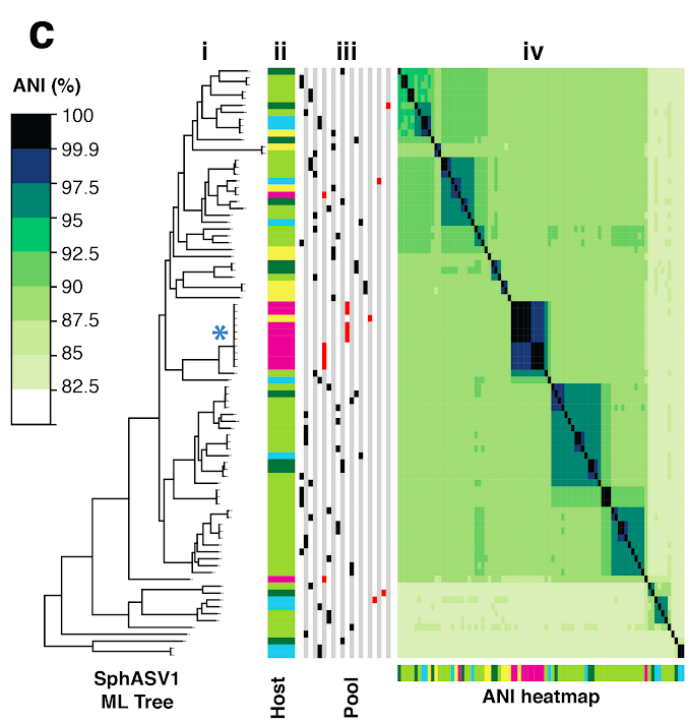

d

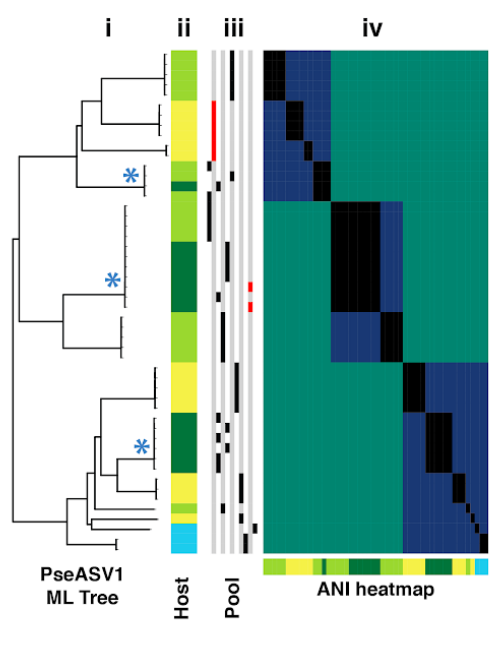

e

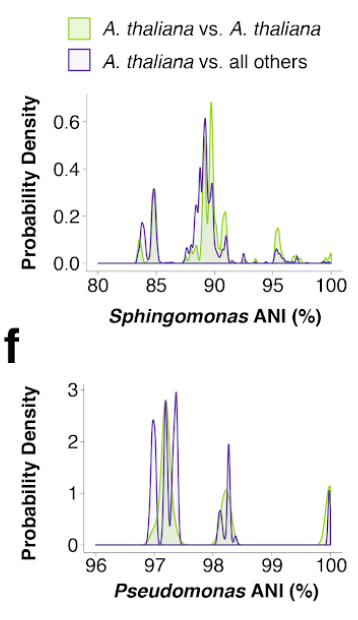

Figure 4. Isolates from other plant species match those isolated from $\boldsymbol{A}$. thaliana | a-b) Plant species from 2018 clustered by Bray-Curtis dissimilarities between relative abundances (RA) for the 10 most abundant I6S rDNA ASVs for each genus. The legend below the figures is shared for both panels. a) Sphingomonas ASVs, with SphASVI as the top row in the heatmap b) Same as (a), but for Pseudomonas ASVs. c) Heatmap revealing genome $\mathrm{ANI}$ of all pairwise comparisons between SphASVI isolates. i: Isolates arranged by a maximum likelihood (ML) core genome tree. The * represents the position of a group of isolates sharing $>99.9 \%$ ANI that derives from different sample pools. ii: plant host of origin is indicated by color, corresponding to the plant legend in (a-b). iii: Isolates from the same sample pool are indicated by red (summer) or black (spring) marks in the same vertical column. iv: heatmap showing pairwise ANI values. d) Same as c, but for PseASVI. e) Distribution of pairwise intra-host isolate ANI compared to inter-host isolate ANI for SphASVI. f) Same as (e), but for PseASVI isolates.

\section{Bulk culture metagenomics reveals strain sharing across plant species}

From our genome-sequenced isolates, it was clear that closely related strains had a regular tendency to colonize diverse hosts. To broaden our survey and extend these observations, we adopted a time and cost-efficient approach to enrich each genus in bulk from plant lysates and sequence the enriched pool as a metagenome. We plated $50 \mu \mathrm{L}$ of glycerol stock from each lysate, corresponding to $\sim 5 \mathrm{mg}$ of original plant material, on selective Pseudomonas or Sphingomonas media and grew colonies en masse (Figure 5a, Supplementary 
Figure 7). This quantity of lysate was chosen empirically for our samples to avoid colonies merging into lawns and allowed visualization of discrete colonies. As a control for lysate viability, we also cultured bacteria from lysates on a non-selective rich LB media. We counted the colonies on each plate after 2 days at room temperature for Pseudomonas, or after 7 days for slower-growing Sphingomonas, to provide a rough estimate of the bacterial load of each genus (Figure 5b). As expected, rich LB media yielded more colonies than selective media, although counts on LB likely vastly underestimate the total bacteria population in each sample, because a single rich medium does not meet nutritional demands for all bacterial taxa, and it furthermore allows fast-growing colonies to overgrow others before they become visible.

To harvest the bacteria, we flooded the plate with phosphate buffered saline (PBS) and then used a flame-sterilized razor blade to scrape the resulting colonies to a pool, from which we made whole metagenome shotgun libraries (Figure 5a, Methods). This culture-dependent metagenomic strategy (6I) allowed us to investigate endophytic-enriched bacteria of our genera of interest, while completely avoiding plant DNA. After sequencing the metagenomes using paired $2 \times 150 \mathrm{HiSeq} 3000$ reads, we mapped the sequences to a comprehensive reference database including all of our local genomes plus selected publicly-available genomes $(45,62)$ (Methods, Supplementary Figure 8). Because not all colonies on our plates belonged to our targeted genus, we also included in our reference database "decoy" genomes of common plant-associated bacteria to capture those "contaminant" reads and help prevent misclassification to our local strains. A total of 192 metagenomes $(119$ Sphingomonas $+74=$ Pseudomonas) passed our quality thresholds. For both genera, as also suggested by the amplicon data in (Figure 4a, 4b), there was also a clear shift in dominant bacteria across seasons, including for those plant taxa such as T. officianale, Moss, and $C$. hirsuta that were present at both timepoints (Figure 5c, 5d). Finally, it was clear that many of the same successfully-colonizing strains were shared widely across plants. In particular, this could be observed for strains associated with SphASVI and PseASVI. Interestingly, the relative representation of both SphASVI and PseASVI isolates in the summer soil samples was low, suggesting that as the next cohort of $A$. thaliana germinates in the fall, migration of these strains onto the seedlings from nearby plants may be more likely than from soil. 
bioRxiv preprint doi: https://doi.org/10.1101/2021.04.06.438366; this version posted April 13, 2021. The copyright holder for this preprint (which was not certified by peer review) is the author/funder, who has granted bioRxiv a license to display the preprint in perpetuity. It is made available under aCC-BY 4.0 International license.

Lundberg et al.

a

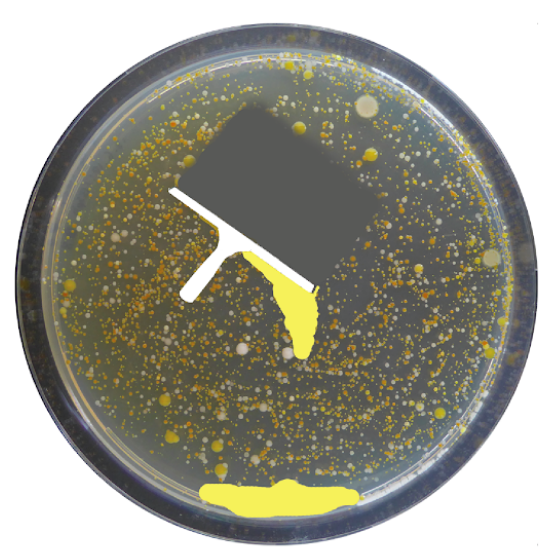

C
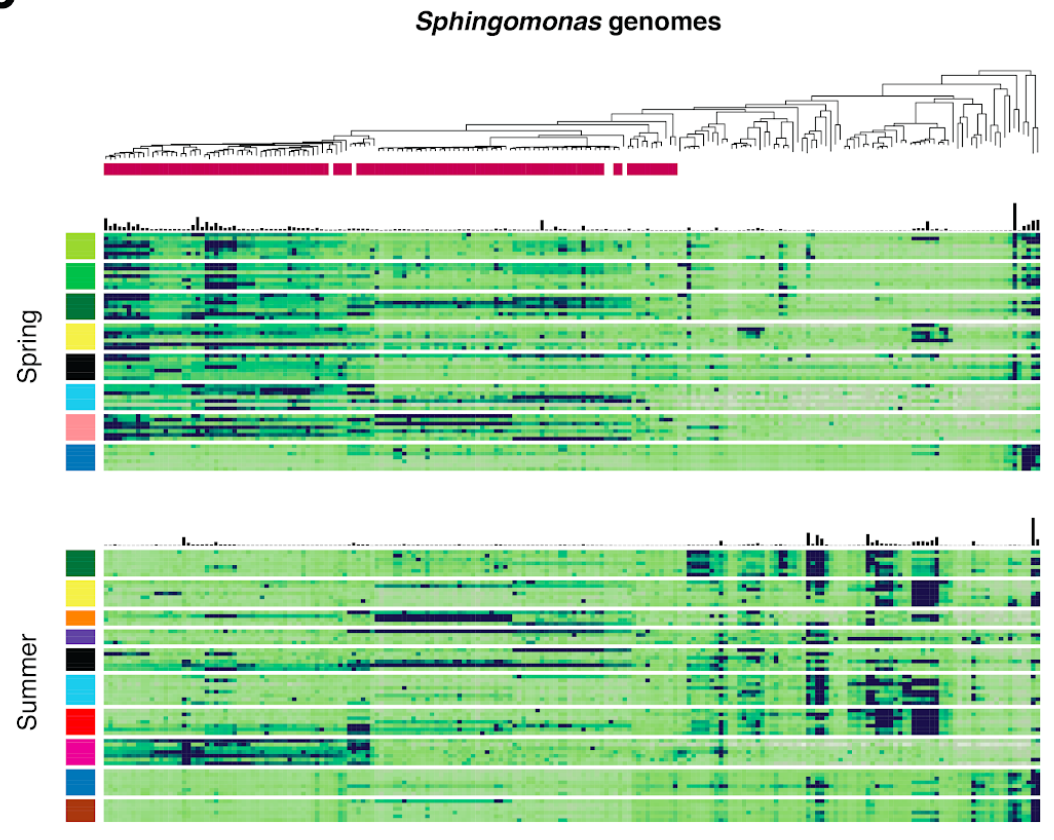
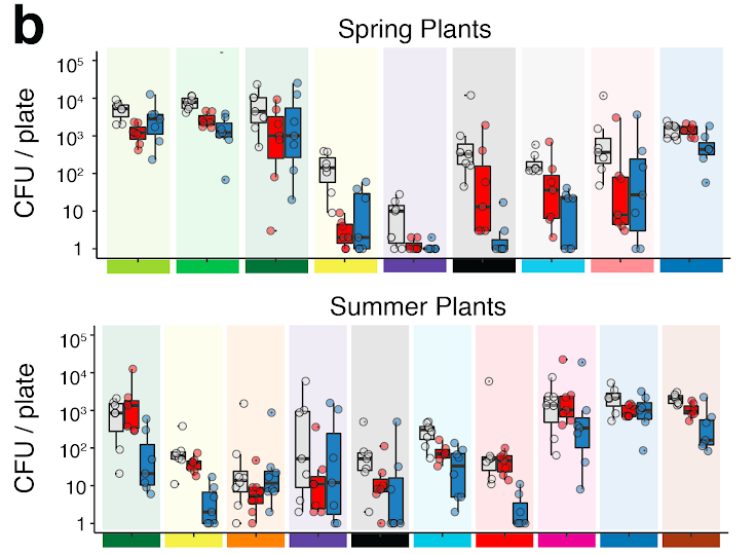

d

Pseudomonas genomes
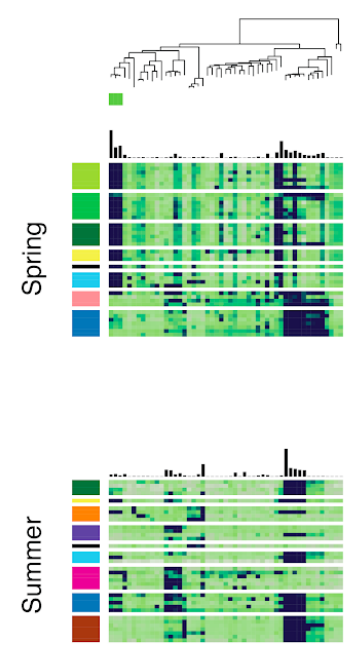

官 LB

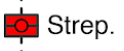

우 Nitro.

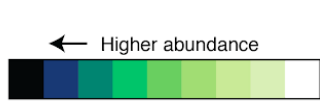

\begin{tabular}{|llll|}
\hline \multicolumn{3}{|c}{ Plant taxa } & P. lanceolate \\
A. thaliana & T. officianale & Epilobium sp. & I. glandulifera \\
D. verna & Sonchus sp. & T. repens & Moss \\
C. hirsuta & Poaceae & FR & Soil \\
\hline
\end{tabular}

Figure 5: Metagenomics of cultured bacteria reveals strain sharing across plant species | a) Cartoon demonstrating the process of generating and harvesting bulk culture metagenomes. b) Colony forming units for each plant species (see color legend, bottom left) on media containing no antibiotic (LB), Sphingomonas-selective streptomycin (Strep) media, or Pseudomonas-selective nitrofurantoin (Nitro) media. Each plate represents about $4.5 \mathrm{mg}$ fresh weight of original leaf material. c) Heatmap showing fourth-root transformed reads from each Sphingomonas bulk culture metagenome (rows, colors from plant taxa legend below) that map to a Sphingomonas local reference genome (columns), for the spring collection (top) and the summer collection (bottom). The genetic relatedness of the local reference genomes is shown by a maximum likelihood (ML) tree above the heatmap. Those reference genomes associated with SphASVI are indicated under the ML tree in magenta. Darker colors in the heatmap correspond to genomes to which a greater fraction of reads map. d) Same as c, showing Pseudomonas bulk culture mapping to Pseudomonas reference genomes. Reference genomes associated with PseASVI are indicated under the $M L$ tree in green. 


\section{Discussion}

Most microbes that live in or on multicellular organisms do not have an obligate relationship with any specific multicellular species, but rather are better adapted to some (hosts) than to others (nonhosts) $(63,64)$. We sought to use genomic techniques to characterize, at the strain level, the extent of host specialization for the two bacterial genera that are locally most abundant in the phyllosphere of the host plant $A$. thaliana. We found a higher genomic diversity of Sphingomonas than for Pseudomonas, even among those sharing the same I6S rDNA sequence, highlighting the importance of strain-resolved techniques to address this question in wild ecosystems. To this end we employed direct culturing and sequencing of individual isolates, as well as bulk-culture metagenomics (Figure 5). Although our techniques enable culture of genetically diverse Sphingomonas and Pseudomonas with low bias (Figure If, $\mathrm{Ig}$ ), bulk culture metagenomics will overrepresent strains that grow faster on the culture media. Therefore, this technique is best thought of as a powerful way to screen for strains of interest in a field site and to qualitatively measure differences in strain membership across plants, rather than to quantitatively characterize the relative strain abundance within a sample. Strain distribution across seasons and other plant species at the same site point to potential explanations for the contrasting colonization patterns of these genera.

Our previous work characterizing PseASVI/PV-ATUE5 suggested that much of its standing genetic variation predates $A$. thaliana colonizing SW Germany ( /8), and we had puzzled how ancient variants are apparently able to continue to coinfect the entire population in this pathosystem, in contrast to agricultural systems epidemics are typically monomorphic with a rapid turnover of pathogenic isolates within a few years $(65,66)$. The present study begins to answer this question. First, PseASVI/PV-ATUE5 strains efficiently colonize other local plant species besides $A$. thaliana, especially other Brassicaceae, implying that their performance on these additional hosts may be at least equally, if not more important to their long-term success than their exploitation of $A$. thaliana as a host. The Pseudomonas strains we observed on $A$. thaliana also persist through the summer on other hosts when there are no living $A$. thaliana plants. Currently, we do not know how important different hosts are for different subclades of PseASVI/PV-ATUE5, but with a substantial number of host species together with genetic heterogeneity in each host, one can easily see how it is difficult for any one strain to prevail and to come to dominate the entire Pseudomonas population. In contrast, in a crop monoculture genetically-identical hosts provide more consistent and uniform challenges for a pathogen, making it more likely for a single strain to become dominant. A second explanation for the lack of a single emergent strain is that the pathogenic nature of PseASVI/PV-ATUES is strongly context-dependent, and apparently more so than other described Pseudomonas pathogens such as Pst DC3000. In an agar plate system, disease caused by PseASVI/PV-ATUE5 was much more severe than that of Pst DC3000, but in potting soil, PseASVI/PV-ATUE5 failed to cause disease symptoms and grew more slowly than Pst DC3000 in wild-type plants. Consistent with fitness 
effects of PseASVI/PV-ATUE5 being greatly modulated by the environment, we saw few disease symptoms on field-collected plants at the time of collection, regardless of their Pseudomonas load.

Compared to PseASVI/Pv-ATUE5, Sphingomonas strains that shared the most abundant V3V4 Sphingomonas ASV, SphASVI, were more than three times as diverse by nucleotide identity in their core genomes. SphASVI isolates differed in type 4 and type 6 secretion system presence, anoxygenic photosynthetic ability, plasmid presence, and likely in other unidentified features that are likely to affect host colonization potential or intermicrobial competition. The plasmid count, up to three per strain in our closed genomes, suggests that the Sphingomonas genetic tool kit may be highly modular. We observed SphASVI in diverse I6S rDNA datasets worldwide, including high abundances on Boechera stricta in North America (/3), and while the extent of genome variation among SphASVI strains in SW Germany makes it difficult to predict genomic features, it will be highly interesting to determine the global diversity in this group of Sphingomonas strains.

This study also demonstrated that apart from SphASVI, the genus Sphingomonas is not only abundant, but consistently so across plants (Figure I). It also colonizes diverse plants at our field site (Supplementary Figure 3), a result consistent with reports of high abundances on leaves of diverse plants such as maize (I4), poplar (IO,II), and others (I0). The different colonization patterns of the genera Pseudomonas and Sphingomonas provide clues about their lifestyle strategies. The fact that Pseudomonas populations vary greatly in size between plants, occasionally reaching high abundances as homogenous blooms of PseASVI/PV-ATUE5 (/8), suggests that different strains may compete for resources and share the same niche, making stable coexistence within a plant less likely. In contrast, Sphingomonas loads varied little across plants, regardless of the load of other bacteria (Figure la), and the diversity of Sphingomonas ASVs in each plant was also higher. The more balanced coexistence of different Sphingomonas strains may mean that each occupies a different niche. To what extent these bacteria inhabit spatially-distinct parts of the leaf or grow as biofilms is unknown; future direct visualisation techniques will help resolve this.

With Pseudomonas and Sphingomonas among the most abundant genera of leaf bacterial communities, and both genera having epiphytic and endophytic lifestyles (Figure Ic), they may frequently interact. Because it reaches such high abundances on and in leaves, Sphingomonas metabolic needs likely substantially reduce substrates of value to other phyllosphere microbes (33), a feature that may contribute to the protective effects of various strains against bacterial and fungal pathogens and contribute to their effects on overall community structure $(5,3 /)$. However, in at least one known case, a Sphingomonas strain secretes an extracellular small molecule that attenuates the virulence of a bacterial pathogen $(2 I)$, indicating that protective mechanisms likely go beyond substrate competition. Although we estimate that in our culture collection only a minority of Sphingomonas strains have protective ability against PseASVI/Pv-ATUE5 or Pst DC3000, the high bacterial titres we inoculated and the gnotobiotic 
environment in which we observed the strongest effects may limit transferability of our results to the field, especially as the most protective isolate had a I6S rDNA sequence that was not among the more abundant on field plants. However, the high diversity of Sphingomonas genomes and the fact that we saw some antagonism suggests there is more to be discovered. The plant protective $S$. melonis $\mathrm{FrI}$ induces transcriptional changes in $A$. thaliana (53), and likely other strains similarly are sensed directly by the plant. The overall implications of Sphingomonas populations on leaves will be important to understand, both for their direct impacts on plant evolution, but also for their role in structuring wild microbial communities.

\section{Materials and Methods}

\section{Plant collection and lysate glycerol stock preparation}

Plants were harvested at Eyach (Starzach) Germany (Supplementary Figure I). The spring visit occurred on the 20th of April, 2018, and the summer visit occurred on the 14th of September, 2018. For each plant species, we pooled together entire leaves from at least 6 independent plants per sample, and collected 7 such independent samples. After bringing samples back to the lab, we surface-sanitized them in 70\% ethanol for $45-60 \mathrm{~s} \mathrm{(55),} \mathrm{ground} \mathrm{the}$ fresh tissue using a sterile mortar and pestle in a volume of PBS proportional to the sample's fresh weight (7.4 mL PBS per gram of tissue), and mixed the resulting lysate with glycerol to make $-80^{\circ} \mathrm{C}$ freezer stocks with a final glycerol concentration of $\sim 27 \%$, suitable both for direct DNA extraction and culturing.

\section{Isolating individual Sphingomonas}

Most Sphingomonas isolates (Supplementary Table 2) were cultured from glycerol-frozen A. thaliana lysates that were originally processed and stored on December II, 20I5 and March 3, 2016 (18). Briefly, we processed two leaves each per $A$. thaliana rosette. Each leaf was washed in $75 \% \mathrm{EtOH}$ for 3-5 s, the ethanol was allowed to evaporate in a sterile hood, and the leaf was ground in $10 \mathrm{mM} \mathrm{MgSO}_{4}$ before being mixed with glycerol to a final concentration of 15\%-30\%. The glycerol stocks were stored at $-80^{\circ} \mathrm{C}$. From each sample, $75 \mathrm{~mL}$ of lysate was plated on large petri plates (I45 x $20 \mathrm{~mm}$, Greiner Bio One International $\mathrm{GmbH}$, Frickenhausen, Germany) containing low sodium Luria broth (LB, $10 \mathrm{gL}$ peptone, $5 \mathrm{~g} / \mathrm{L}$ yeast extract, $5 \mathrm{~g} / \mathrm{L} \mathrm{NaCl}$ ) and I.5\% agar supplemented with $100 \mathrm{mg} / \mathrm{mL}$ cycloheximide to suppress fungi (SERVA Electrophoresis $\mathrm{GmbH}$ ) and $100 \mathrm{mg} / \mathrm{mL}$ streptomycin (Thermo Fisher Scientific, Karlsruhe, Germany). Plates were incubated at room temperature for 5 to 10 days, then stored at $4^{\circ} \mathrm{C}$ until processing. The remaining Sphingomonas isolates from pooled $A$. thaliana and other plant species were recovered similarly by plating lysates on selective media (see section "Bulk culture and additional cultured isolates"). 
Up to 16 colonies per plate were randomly picked and transferred to 24-well plates (CELLSTAR®, Greiner Bio One International GmbH, Frickenhausen, Germany) containing the same selective LB agar, and incubated for 5-10 additional days as necessary to create a small bacterial lawn. All bacteria were cultivated on agar, as we observed that many grew poorly in liquid media. Bacteria were then scraped from the agar with a sterile loop and transferred to a $2 \mathrm{~mL}$ screw cap tube (Starstedt, Nümbrecht, Germany) filled with $300 \mathrm{ml}$ of PBS (we later switched to $300 \mathrm{~mL}$ of liquid LB media instead of PBS, which improved survival). Three sterile glass balls ( $Æ 2.85-3.45 \mathrm{~mm}$ or $Æ$ 0.25-0.5 mm) (Carl Roth $\mathrm{GmbH}$, Karlsruhe, Germany) were added to each screw cap to help dissociate (but not lyse) clumped bacterial cells, and tubes were shaken in a FastPrep 24 ${ }^{\mathrm{TM}}$ 5G homogeniser (MP Biomedicals, Eschwege, Germany) at speed $4.0 \mathrm{~m} / \mathrm{s}$ for 10 seconds. From the mixed cell suspension, $250 \mathrm{~mL}$ was stored at $-80^{\circ} \mathrm{C}$ in $\sim 27 \%$ glycerol.

\section{Sphingomonas DNA isolation for short read sequencing}

The remaining $50 \mathrm{~mL}$ was mixed with $150 \mathrm{~mL}$ of sterile PBS and transferred to a semi-skirted 96-well PCR microplates (Axygen ${ }^{\mathrm{TM}}$ ) for DNA extraction. Bacterial cell suspensions were lysed by incubation with lysozyme $\left(100 \mathrm{mg} / \mathrm{mL}\right.$ final concentration) at $37^{\circ} \mathrm{C}$ for 30 min followed by incubation with sodium dodecyl sulfate SDS ( $1.5 \%$ final concentration) at $56^{\circ} \mathrm{C}$ for I- $2 \mathrm{~h}$. Next, $1 / 3$ volume $(66 \mu \mathrm{L})$ of $5 \mathrm{M}$ potassium acetate $\left(\mathrm{CH}_{3} \mathrm{COOK}\right)$ was added to each well to precipitate the SDS and other cytosolic components. The 96-well plates were centrifuged at maximum speed for $20 \mathrm{~min}$ to pellet the precipitate, and the supernatant transferred to a new 96-well plate for genomic DNA purification using Solid Phase Reversible ilmmobilization (SPRI) magnetic beads (67). Briefly, home-made SPRI bead mix adapted from (67) was thoroughly mixed with our samples at a ratio of $0.6: 1$ bead to sample ratio and incubated for 15-20 min. The plates were placed on a magnet for $5 \mathrm{~min}$ and the supernatant was removed. Following two $80 \% \mathrm{EtOH}$ washes, the beads were air-dried and resuspended in $50 \mu \mathrm{L}$ elution buffer (EB, $10 \mathrm{mM}$ Tris, $\mathrm{pH} 8.0$ ). After an overnight incubation at $4^{\circ} \mathrm{C}$, the plates were placed in the magnet and the elution buffer containing the DNA was transferred into a new 96-well PCR plate.

\section{Bulk culture and additional cultured isolates}

For Pseudomonas and Sphingomonas bulk culture analysis, approximately $50 \mathrm{mg}$ of plant lysates collected from Eyach in 2018 was scooped from the frozen glycerol stocks at $-80^{\circ} \mathrm{C}$, and after thawing, $50 \mu \mathrm{L}$ of the thawed lysate was pipetted onto $2 \%$ agar LB plates $(200 \mathrm{~mm}$ diameter), using an additional $150 \mu \mathrm{L}$ of sterile PBS to aid in spreading. The LB medium was supplemented with $100 \mu \mathrm{g} / \mathrm{mL}$ cycloheximide and $100 \mu \mathrm{g} / \mathrm{mL}$ streptomycin for Sphingomonas bulk culturing, and $100 \mu \mathrm{g} / \mathrm{mL}$ cycloheximide and $100 \mu \mathrm{g} / \mathrm{mL}$ nitrofurantoin (Sigma-Aldrich, 
Steinheim am Albuch, Germany) for Pseudomonas bulk culturing (/8). Plates were incubated at room temperature 5 days for Sphingomonas or 1.5-2 days for Pseudomonas.

Individual colonies from selected plates were randomly picked to 24 -well plates, as described above. To harvest the remaining bacterial colonies in bulk, plates were soaked for 5 min with $4 \mathrm{~mL}$ of PBS, and the surface was scraped with a flame-sterilized razor blade to loosen adherent bacteria. The plate was tilted to form a pool of PBS at the lower end, and the scraped bacteria were mixed into the PBS pool by pipetting up and down. An appropriate aliquot of the mixed suspension was then transferred to a $2 \mathrm{~mL}$ centrifuge tube, such that the eventual pellet would extend a maximum of $5 \mathrm{~mm}$ from the base of the tube (which approaches an upper limit for efficient and uniform DNA extraction using our methods). The amount of bacteria transferred varied depending on the density of colonies on the plates.

\section{DNA extraction from bulk culture bacterial pellets and plant lysates}

For bulk culture bacterial pellets, the final bacterial pellets were resuspended in at least $750 \mu \mathrm{L}$ of DNA lysis buffer containing $10 \mathrm{mM}$ Tris $\mathrm{pH} 8.0,10 \mathrm{mM}$ EDTA, $100 \mathrm{mM} \mathrm{NaCl}$, and I.5\% SDS. Especially large pellets (greater than $5 \mathrm{~mm}$ from the bottom of the tube) were suspended in proportionally greater volumes of buffer to ensure an efficient lysis, and $750 \mu \mathrm{L}$ was used for lysis. For DNA extraction from the plant lysates in glycerol, $400 \mathrm{uL}$ of glycerol lysates was mixed with $400 \mu \mathrm{L}$ of the DNA lysis buffer described in the previous sentence, but with $3 \%$ SDS instead of I.5\% SDS to yield a final SDS concentration of $1.5 \%$. The suspensions were pipetted to a screw cap tube containing $\sim 0.5 \mathrm{~mL}$ sterile garnet beads (Bio Spec Products Inc., USA) and homogenized in a FastPrep $24^{\mathrm{TM}} 5 \mathrm{G}$ homogeniser at speed $6.0 \mathrm{~m} / \mathrm{s}$ for I min. The tubes were next centrifuged at $10000 \times \mathrm{g}$ for $5 \mathrm{~min}$, and the supernatant (about $600 \mu \mathrm{L}$ ) mixed with $200 \mu \mathrm{L}$ sterile $5 \mathrm{M}$ potassium acetate in a I mL 96-well plate (Ritter Riplate $\mathbb{R}$ 4300I-0016, Schwabmünchen, Germany) to precipitate the SDS. The plates were spun at 5000 $x \mathrm{~g}$ for $10 \mathrm{~min}$ and the supernatant transferred to a new I $\mathrm{mL}$ deepwell plate. The resulting supernatant was centrifuged a second time to clear out remaining plant material and precipitate. Finally, $360 \mu \mathrm{L}$ SPRI beads were added to $600 \mu \mathrm{L}$ of the supernatant. After mixing and incubating on a 96-Well Magnet Type A (Qiagen, Hilden, Germany) the beads were cleaned with $80 \%$ ethanol and DNA was eluted in $100 \mu \mathrm{L}$ of EB.

\section{6S rDNA V3-V4 amplicon sequencing}

The I6S rDNA V3-V4 region was amplified using the 2-step protocol described for V4 amplicons in (9), with the exception that the forward PCR primer was 34IF (Supplementary Table I), and due to this different forward primer, the annealing step in the first PCR was done at $55{ }^{\circ} \mathrm{C}$ instead of $50{ }^{\circ} \mathrm{C}$ in (9). In addition, because the amplicons were longer than the V4 amplicons in (9), the libraries were sequenced on MiSeq instrument (Illumina) with a V3 $2 \times 300$ bp reagent kit instead of a V2 $2 \times 250$ bp reagent kit. This allowed overlap and assembly 
of the forward and reverse reads. The frameshifts built into the primers used in the first PCR made the addition of Illumina PhiX control library to increase sequence diversity unnecessary [27].

\section{Bacterial whole-genome sequencing and bulk culture metagenome sequencing with} short reads

DNA from each bacterial isolate, or from each metagenome, was quantified by Quant-iT ${ }^{\mathrm{TM}}$ PicoGreen ${ }^{\mathrm{TM}}$ dsDNA (Invitrogen ${ }^{\mathrm{TM}}$ ) in a Magellan Infinite 200 PRO plate reader (Tecan Trading AG, Switzerland) and diluted and normalised to $0.5 \mathrm{ng} / \mu \mathrm{l}$ as a prior step to library construction. Bacterial DNA libraries were constructed using an adapted Nextera ${ }^{\mathrm{TM}}$ protocol for small volumes $(18,68)$. In brief, $2.5 \mathrm{ng}$ of DNA was sheared using Nextera Tn5 transposase (Illumina, Inc), and Nextera sequencing adapters were added though 12 cycles of PCR as previously described (18). An aliquot of each library was run in an agarose gel for quality control, and the remainder of the library was purified using SPRI beads to remove primers at a ratio I.5:I beads to PCR product. The clean DNA was eluted in $40 \mu \mathrm{L}$ of EB and the concentration of the final product was quantified with PicoGreen. Libraries were pooled in an equimolar ratio. To increase the concentration of the pool to enable further size selection procedures, the pooled library was concentrated by first precipitating the DNA by mixing with it with an equal volume of a solution containing I part sodium acetate and 8 parts isopropanol, passing the solution over an EconoSpin Mini Spin Columns (Epoch Life Science Inc.), washing the column twice in $70 \%$ ethanol, and eluting in $50 \mu \mathrm{L}$ EB. The resulting multiplexed, concentrated library molecules were size selected to keep fragments between 350 and 700 bp using a $1.5 \%$ cassette in a BluePippin instrument (Sage Science, Inc). After adjusting the concentration of each size-selected pool to $2.5 \mathrm{nM}$, the DNA was sequenced with $2 \times 150$ bp paired-end reads on a HiSeq 3000 instrument (Illumina inc, San Diego, USA).

\section{Short-read genome assembly and annotation}

Genomes were assembled using SPAdes genome assembler version 3.11 .0 correcting for mismatches and short indels (--careful) and k-mer sizes of $21,33,55,77,99$ and I 27 (-k) (69). Draft genomes were corrected using Pilon version 1.20 with standard parameters (70). Annotation of bacterial genomes was accomplished using Prokka version I.I2 using the --compliant parameter (43). Coverage and N50 statistics were measured using custom scripts, including the N50.sh script from the GitHub repository of Henk den Bakker (7I). The completeness of the genome was assessed using BUSCO version 2.0 (4l) selecting proteobacteria lineage and the gene set (proteins) assessment (-m prot). 


\section{Production and assembly of closed Sphingomonas genomes}

Assembly of closed Sphingomonas genomes required a separate DNA preparation and library production for sequencing on an Oxford Nanopore MinION instrument. First, 12 Sphingomonas isolates were each bulked on $15 \times 15 \mathrm{~cm}^{2} \mathrm{LB}$ plates with $100 \mu \mathrm{m} / \mathrm{mL}$ streptomycin. After 2-5 days, depending on the growth rate of each strain, the bacterial lawn was harvested, and $100 \mathrm{mg}$ of bacteria was mixed with $800 \mu \mathrm{L}$ lysis buffer, and DNA was extracted and purified using the homemade SPRI beads exactly as described above for bulk culture lysates, including the harsh bead beating. We noticed that bead beating did not shear DNA below $10 \mathrm{~kb}$, and fragments greater than approximately $7 \mathrm{~kb}$ are sufficiently long to span repeated regions in bacterial genomes (72). The harsh bead beating during the lysis step naturally sheared the DNA to approximately $15-20 \mathrm{~kb}$, and the 0.6 : 1.0 SPRI bead cleanup removed most of the smaller fragments, so no additional shearing or size selection was performed. DNA was eluted from the SPRI beads in $400 \mu \mathrm{L}$ EB. Because some DNA extracts remained discolored or viscous following the SPRI purification, the DNA was further purified by mixing with it with an equal volume of chloroform. The aqueous phase was collected and the HMW DNA was precipitated by mixing it with an equal volume of a solution containing I part sodium acetate and 8 parts isopropanol. Precipitated DNA was pelleted by centrifugation at $20,000 \times \mathrm{g}$ for 5 minutes. The pellet was washed twice in $70 \%$ ethanol and eluted again in 400 $\mu \mathrm{L}$ EB.

Pure DNA was prepared for sequencing on the Nanopore MinION using the Nanopore-recommended protocol entitled "ID Native barcoding genomic DNA" using SQK-LSK 109 kit with barcode expansions NBCI04 and NBCII 4 for 24 samples. Briefly, DNA concentration was adjusted to I $\mu \mathrm{g}$ of DNA diluted in $49 \mu \mathrm{L}$ of NFW water (Ambion). From this $48 \mu \mathrm{L}$ were treated with NEBNext reagents for FFPE and end repair as well as $\mathrm{dA}$-tailing. The end-repaired libraries were cleaned with Agencourt AMPure XP beads at a I:I ratio and

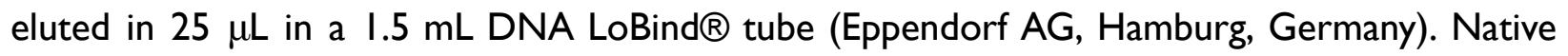
barcodes were attached by ligation, the solution was again cleaned with AMPure beads at a I:I ratio, and concentration of all barcoded-added samples were measured using a Qubit (Thermo Fisher) fluorometer and pooled at equimolar ratios for a total of $700 \mathrm{ng}$. Finally, sequencing adapters were added to the pool by ligation. LFB was selected for washing in the final clean-up with AMPure beads. The library was prepped and loaded into an FLO-MINI06 RevD R9.4.I flow cell following the manufacturer's instructions and sequencing was run for $24 \mathrm{~h}$.

To assemble closed Sphingomonas genomes, Guppy package version 3.0.3 (https://nanoporetech.com/) was first employed to perform initial base calling to produce raw read and quality assessment in the FASTQ format as recommended by (73). Next, the samples were demultiplexed using qcat. Draft contigs were then assembled de novo by using mini_assemble which is part of the Pomoxis toolkit (version 0.3.6, 
https://github.com/nanoporetech/pomoxis) using default parameters for de-novo assembly employing miniasm (74) and four rounds of long-reads-based polishing with minimap2 and Racon. Each of the genomic consensus assembly was further improved by additional 4 rounds of long-reads-based polishing with Racon followed by one additional round using medaka_consensus (package version 0.6.5, https://github.com/nanoporetech/medaka). To enhance base corrections, an additional polishing step using high-quality Illumina short reads from the same Sphingomonas strains was used. First, the short reads were mapped onto the assembled Sphingomonas genome, using Burrows-Wheeler Alignment (BWA) with BWA-MEM (75). Next, these mapped reads were used to correct the assembly using Pilon version 1.23 with default parameters (70). Assessment of genome completeness and annotations were performed in the same way as short-read draft genomes.

\section{Pan-genome and phylogenetics analysis}

The panX pan-genome pipeline (44) was used to assign orthology clusters and construct the phylogenetic tree, taking as input the Genbank format files (.gbk) from Prokka (previous section). The following parameters were used for the panX analysis: the divide-and-conquer algorithm (-dmdc), a size of 50 strains per subset to run DIAMOND (-dcs 50) (76), and a soft core genome cutoff of $70 \%$ that includes all genes present in $>70 \%$ of the strains as part of the core genome (-cg 0.7). Genomes included in each panX run are indicated in Supplementary Table 2.

\section{Processing bulk culture metagenomic reads}

A first quality control of raw sequencing data was performed using Skewer version 0.2.2 (77) to trim raw reads and remove highly degenerative reads $(-n)$ or reads shorter than 20 bp (-I 20). For those samples with a total yield of at least $500 \mathrm{Mb}$, the filtered reads were mapped with BWA-MEM (75) using standard parameters against a custom-made reference database (described in the next section). Those reads mapping with a quality score of 30 or higher were output in a BAM file using SAMtools (78). Duplicated reads were removed from BAM files using the MarkDuplicates command in Picard tools (http://broadinstitute.github.io/picard/) version 2.0.I using default parameters. SAMtools -stats and -fastq commands were used to retrieve BWA-MEM mapping statistics and convert the BAM files back to FASTQ files, respectively (Supplementary Figure 8).

\section{Custom local reference database}

Metagenome reads from the Sphingomonas or Pseudomonas bulk cultures were mapped to a three part custom-made reference database of bacterial genomes. First, "Decoy" genomes contained bacteria from other genera, and were used to help classify reads from contaminant bacteria. The collection of Decoy genomes was made by downloading the $A$. thaliana 
phyllosphere, root, and soil isolates from (62) and removing Pseudomonas when mapping Sphingomonas, or removing Sphingomonas when mapping Pseudomonas. Three different genome sets were combined with distinctive headings to allow later recovery of mapped reads:

DECOY: A set of bacterial genomes ( 430 genomes) found in $A$. thaliana phyllosphere, roots, and soil surrounding the plants. Published in (62). Decoy genomes have the mission to capture contaminant reads.

REFSEQ: A set of bacterial genomes of Pseudomonas or Sphingomonas found in the NCBI Reference Sequence Database (45).

LOCAL: A set of bacterial genomes of interest sequenced in-house. This includes 165 genomes representative of local Pseudomonas isolates sequenced by (18) and all the single Sphingomonas and Pseudomonas genomes from this study.

\section{Genome similarity comparisons}

Briefly, to generate similarity matrices for Sphingomonas and/or Pseudomonas genome comparisons using MASH (version 2.I)(42), we used the formula $100 \times(I-M D)$, where MD is the MASH distance, to convert MASH distances to similarity scores. To calculate average nucleotide identity (ANI), we used FastANI (79) For similarity matrices Heatmaps of similarity scores were illustrated using the function "heatmap.2" in the R package "gplots" (80).

\section{Inoculation, infection, and phenotyping in 24-well plates}

Plant cultivation: Each well of a 24-well plate (Greiner) was filled with $1.5 \mathrm{~mL}$ of $1 \%$ agar (Duchefa) containing $1 / 2$ strength Murashige-Skoog (MS) medium with MES buffer. A. thaliana seeds (accession Ey 15-2, CS76309) were surface-sterilized by submerging in $70 \% \mathrm{EtOH}$ with $0.01 \%$ Triton X-100 for $1 \mathrm{~min}$, then submerging in 10\% household bleach solution for $12 \mathrm{~min}$, and finally washing three times with sterile water. The seeds were then stratified at $4^{\circ} \mathrm{C}$ for 3 days in water, and then were pipetted onto the agar (I seed/well). Excess water after distributing seeds was removed by pipetting.

Inoculation and infection: Freshly-planted, ungerminated seeds were inoculated with 4 $\mu \mathrm{L}$ of $10 \mathrm{mM} \mathrm{MgCl}$ or with Sphingomonas sp. suspended in the same amount of buffer to an optical density at $600 \mathrm{~nm}\left(\mathrm{OD}_{600 \mathrm{~nm}}\right)$ of 0.5 . The Sphingomonas had been previously cultivated for 5 days on selective LB agar plates with $100 \mathrm{mg} / \mathrm{mL}$ streptomycin, were scraped from the plates with a sterile loop, and were washed twice by centrifugation and resuspension in $\mathrm{MgCl}_{2}$ to remove residual antibiotics. Inoculated seeds were germinated and seedlings were cultivated for 10 days in growth chambers at $21{ }^{\circ} \mathrm{C}$ with 16 hours of light. The seedlings were then challenged with $100 \mu \mathrm{L}$ of $10 \mathrm{mM} \mathrm{MgCl} 2$ or with Pseudomonas suspended in the same amount of buffer to $\mathrm{OD}_{600 \mathrm{~nm}}=0.01$. The bacteria were drip-inoculated by pipette to the center of each rosette. Plates were sealed with Parafilm and returned to the growth chamber for 7 days. 
Plant phenotyping: On $0,2,4$, and 7 days post inoculation, rosettes were imaged in the plates with a custom procedure to eliminate glare. Briefly, an opaque box was filled with a LED light source and covered with a sturdy translucent paper surface to diffuse the light. Each plate was placed on top of the paper in a defined position, and the backlighting allowed imaging from above without removing the lids. Pictures were taken using a LUMIX DMC-TZ7I digital camera (Panasonic Co., Osaka, Japan) without flash. Images were processed similarly to that described in $(8 I)$. Briefly a predefined mask was used to extract each plant in the image, and automatic segmentation based on pixel color was applied to recognize plant leaves from background. The leaf area of each plant was then calculated based on the segmented plant images.

\section{Inoculation, infection, phenotyping, and hamPCR of plants on potting soil}

Plant cultivation: $A$. thaliana Ey $15-2$ seeds were surface-sterilized, stratified for 4 days in sterile water at $4^{\circ} \mathrm{C}$, and sowed on potting soil (CL T Topferde; www.einheitserde.de) in $7 \mathrm{~cm}$ pots (PL 2832/20, Pöppelmann GmbH, Lohne, Germany). Seedlings were germinated and cultivated under short day (8 hr light) growing conditions at $23^{\circ} \mathrm{C}$ and $65 \%$ relative humidity, illuminated by cool white fluorescent light of 125 to $175 \mu \mathrm{mol} \times \mathrm{m}^{-2} \times \mathrm{s}^{-1}$.

Inoculation and infection: Two weeks after sowing, seedling leaves were sprayed ad- and ab- axially with Sphingomonas strains cultivated identically as for inoculation in 24-well plates as described above, but resuspended in $10 \mathrm{mM} \mathrm{MgCl}$ buffer to a concentration of $\mathrm{OD}_{600 \mathrm{~nm}}=1.0$. Plants were also sprayed with heat-killed (boiled) Sphingomonas prepared by mixing equal parts of all strains after they had been resuspended at $\mathrm{OD}_{600 \mathrm{~nm}}=1.0$ in $\mathrm{MgCl}_{2}$ and boiling the resulting solution for 10 minutes. Humidity domes were kept on the flats for 48 hours. On the fourth day following Sphingomonas treatment, plants were sprayed with Pseudomonas strains also cultivated identically as for 24-well plates, but resuspended in $10 \mathrm{mM} \mathrm{MgCl}$ buffer to a concentration of $\mathrm{OD}_{600 \mathrm{~nm}}=1.0$. A heat-killed Pseudomonas mix was also prepared, as described above. Prior to spray-inoculating Pseudomonas, the surfactant Silwet L-77 added at $0.04 \% \mathrm{v} / \mathrm{v}$ following the protocol in (54). Humidity domes were kept on the flats for 72 hours.

Plant phenotyping: Five days $(\mathrm{I} 20 \mathrm{~h})$ post inoculation, overhead images of pots arranged in the flat were taken from a height of $\sim 1.5 \mathrm{M}$ with a LUMIX DMC-TZ7I digital camera. Because the position of each pot in the flat and the position of each plant in the pot was not fixed in the overhead images, identically-sized squares containing each plant were manually cropped from each image and arranged into a montage for each flat using object alignment functions in Adobe Illustrator. The montages were then processed programmatically as described in the previous section by using a predefined mask to extract each plant in the image and counting green pixels.

Confirmation of viable bacteria and DNA extraction: Following plant phenotyping, whole seedlings were harvested to $2 \mathrm{~mL}$ screw-cap tubes (Type I, Sarstedt AG, Nümbrecht, Germany) using flame-sterilized tweezers and scissors, and kept on ice. First, one $5 \mathrm{~mm}$ glass 
bead (Sigma) and $300 \mu \mathrm{L}$ of PBS buffer were added to the tubes and the tubes were shaken at speed $4.0 \mathrm{~m} / \mathrm{s}$ in a FastPrep $24^{\mathrm{TM}} 5 \mathrm{G}$ homogeniser for $20 \mathrm{~s}$ to release viable bacteria from the leaves. From this homogenate, $20 \mu \mathrm{L}$ was directly plated on both Sphingomonas and Pseudomonas selective media to confirm viable bacteria were present at the end of the experiment (not shown). Next, $470 \mu \mathrm{L}$ of DNA lysis buffer containing 3\% SDS as described in "DNA extraction from bulk cultures and plant lysates" above was added to the remaining lysate to make a final SDS concentration of $1.88 \%$. Garnet beads $(0.5 \mathrm{~mL})$ were added to the lysate and DNA was extracted by bead-beating at speed $6.0 \mathrm{~m} / \mathrm{s}$ in the FastPrep $24^{\mathrm{TM}} 5 \mathrm{G}$, and purified as described earlier.

hamPCR to determine bacterial load and composition the bacterial community: hamPCR (60) was performed on seedlings from soil-grown plants using primers for the $A$. thaliana GIGANTEA gene as a host gene and primers for the V4 region of the I6S rDNA (Supplementary Table I), using primers and cycling conditions recommended in (60).

\section{Data availability}

All data in this manuscript are in the process of being deposited to the European Nucleotide Archive (ENA) under the project number PRJEB44I36. At https://www.ebi.ac.uk/ena

\section{Author Contributions}

DSL planned the study. DSL, TLK, OS, RdP-J, and DW collected samples. DSL, RdP-J, PP, and KP processed plant samples, made sequencing libraries, and analyzed data. AB-G helped troubleshoot the agar plate assays. IB developed algorithms for plant phenotyping from photographs. WD helped with panX analysis. DSL, RdP-J, PP, and DW wrote the manuscript, with input from all authors.

\section{Acknowledgements}

We thank Christa Lanz, Manuela Neumann, and Pablo Carbonell for assistance with Nanopore sequencing, Heike Budde for assistance with Illumina sequencing, and Haim Ashkenazy for assistance with the Nanopore genome assembly pipeline. Supported by Human Frontiers Science Program (HFSP) Long-Term Fellowships (LT000565/20I5-L, D.S.L.; LT000348/20I6-L, T.L.K.), ERC Advanced Grant IMMUNEMESIS (340602), the DFG through SPP Priority Program DECRyPT, and the Max Planck Society (DW).

\section{Competing Interests}

The authors declare no competing interests. 
bioRxiv preprint doi: https://doi.org/10.1101/2021.04.06.438366; this version posted April 13, 2021. The copyright holder for this preprint (which

was not certified by peer review) is the author/funder, who has granted bioRxiv a license to display the preprint in perpetuity. It is made available under aCC-BY 4.0 International license.

\section{References}

I. M. L. Avolio, E. J. Forrestel, C. C. Chang, K. J. La Pierre, K. T. Burghardt, M. D. Smith, Demystifying dominant species. New Phytol. 223, I I06-I I 26 (2019).

2. Y. Zhou, H. Gao, K. A. Mihindukulasuriya, P. S. La Rosa, K. M. Wylie, T. Vishnivetskaya, M. Podar, B. Warner, P. I. Tarr, D. E. Nelson, J. D. Fortenberry, M. J. Holland, S. E. Burr, W. D. Shannon, E. Sodergren, G. M.

Weinstock, Biogeography of the ecosystems of the healthy human body. Genome Biol. I4, RI (20I3).

3. S. L. Heaver, E. L. Johnson, R. E. Ley, Sphingolipids in host-microbial interactions. Curr. Opin. Microbiol. 43, 92-99 (2018).

4. A. G. Wexler, A. L. Goodman, An insider's perspective: Bacteroides as a window into the microbiome. Nature Microbiology. 2, 17026 (2017).

5. M. T. Agler, J. Ruhe, S. Kroll, C. Morhenn, S.-T. Kim, D. Weigel, E. M. Kemen, Microbial Hub Taxa Link Host and Abiotic Factors to Plant Microbiome Variation. PLoS Biol. 14, el 002352 (2016).

6. J. A. Vorholt, Microbial life in the phyllosphere. Nat. Rev. Microbiol. 10, 828-840 (2012).

7. T. L. Karasov, M. Neumann, A. Duque-Jaramillo, S. Kersten, I. Bezrukov, B. Schröppel, E. Symeonidi, D. S. Lundberg, J. Regalado, G. Shirsekar, J. Bergelson, D. Weigel, The relationship between microbial biomass and disease in the Arabidopsis thaliana phyllosphere. bioRxiv (2019), p. 8288I4.

8. N. Bodenhausen, M. W. Horton, J. Bergelson, Bacterial communities associated with the leaves and the roots of Arabidopsis thaliana. PLoS One. 8, e56329 (2013).

9. J. Regalado, D. S. Lundberg, O. Deusch, S. Kersten, T. Karasov, K. Poersch, G. Shirsekar, D. Weigel, Combining whole-genome shotgun sequencing and rRNA gene amplicon analyses to improve detection of microbe-microbe interaction networks in plant leaves. ISME J. I4, 2I I6-2130 (2020).

10. H. Kim, M. Nishiyama, T. Kunito, K. Senoo, K. Kawahara, K. Murakami, H. Oyaizu, High population of Sphingomonas species on plant surface. J. Appl. Microbiol. 85, 73I-736 (1998).

II. J. Massoni, M. Bortfeld-Miller, L. Jardillier, G. Salazar, S. Sunagawa, J. A. Vorholt, Consistent host and organ occupancy of phyllosphere bacteria in a community of wild herbaceous plant species. ISME J. (2019), doi:10.1038/s41396-019-053I-8.

12. C. E. Morris, J. R. Lamichhane, I. Nikolić, S. Stanković, B. Moury, The overlapping continuum of host range among strains in the Pseudomonas syringae complex. Phytopathology Research. I, 4 (2019).

13. M. R. Wagner, D. S. Lundberg, T. G. Del Rio, S. G. Tringe, J. L. Dangl, T. Mitchell-Olds, Host genotype and age shape the leaf and root microbiomes of a wild perennial plant. Nat. Commun. 7, I2I5I (2016).

14. J. G. Wallace, K. A. Kremling, L. L. Kovar, E. S. Buckler, Quantitative Genetics of the Maize Leaf Microbiome. Phytobiomes Journal. 2, 208-224 (2018).

15. K. L. Grady, J. W. Sorensen, N. Stopnisek, J. Guittar, A. Shade, Assembly and seasonality of core phyllosphere microbiota on perennial biofuel crops. Nat. Commun. 10, 4135 (2019).

16. C.-J. Dong, L.-L. Wang, Q. Li, Q.-M. Shang, Bacterial communities in the rhizosphere, phyllosphere and endosphere of tomato plants. PLoS One. I4, e0223847 (2019).

17. R. S. C. de Souza, V. K. Okura, J. S. L. Armanhi, B. Jorrín, N. Lozano, M. J. da Silva, M. González-Guerrero, L. M. de Araújo, N. C. Verza, H. C. Bagheri, J. Imperial, P. Arruda, Unlocking the bacterial and fungal communities assemblages of sugarcane microbiome. Sci. Rep. 6, 28774 (20I6).

18. T. L. Karasov, J. Almario, C. Friedemann, W. Ding, M. Giolai, D. Heavens, S. Kersten, D. S. Lundberg, M. Neumann, J. Regalado, R. A. Neher, E. Kemen, D. Weigel, Arabidopsis thaliana and Pseudomonas Pathogens Exhibit Stable Associations over Evolutionary Timescales. Cell Host Microbe. 24, 168-179.e4 (2018).

19. H. C. McCann, E. H. A. Rikkerink, F. Bertels, M. Fiers, A. Lu, J. Rees-George, M. T. Andersen, A. P. Gleave, B. Haubold, M. W. Wohlers, D. S. Guttman, P. W. Wang, C. Straub, J. L. Vanneste, P. B. Rainey, M. D. Templeton, Genomic analysis of the Kiwifruit pathogen Pseudomonas syringae pv. actinidiae provides insight into the origins of an emergent plant disease. PLoS Pathog. 9, el 003503 (2013).

20. T. C. Helmann, A. M. Deutschbauer, S. E. Lindow, Genome-wide identification of Pseudomonas syringae genes required for fitness during colonization of the leaf surface and apoplast. Proc. Natl. Acad. Sci. U. S. A. I I6, 18900-18910 (2019).

2I. H. Matsumoto, X. Fan, Y. Wang, P. Kusstatscher, J. Duan, S. Wu, S. Chen, K. Qiao, Y. Wang, B. Ma, G. Zhu, Y. Hashidoko, G. Berg, T. Cernava, M. Wang, Bacterial seed endophyte shapes disease resistance in rice. Nat Plants. 7, 60-72 (202I). 
bioRxiv preprint doi: https://doi.org/10.1101/2021.04.06.438366; this version posted April 13, 2021. The copyright holder for this preprint (which

was not certified by peer review) is the author/funder, who has granted bioRxiv a license to display the preprint in perpetuity. It is made available under aCC-BY 4.0 International license.

Lundberg et al. Contrasting patterns of microbial dominance

22. N. C. Snelders, H. Rovenich, G. C. Petti, M. Rocafort, G. C. M. van den Berg, J. A. Vorholt, J. R. Mesters, M. F. Seidl, R. Nijland, B. P. H. J. Thomma, Microbiome manipulation by a soil-borne fungal plant pathogen using effector proteins. Nat Plants. 6, I365-1374 (2020).

23. C. Vogel, G. Innerebner, J. Zingg, J. Guder, J. A. Vorholt, Forward genetic in planta screen for identification of plant-protective traits of Sphingomonas sp. strain FrI against Pseudomonas syringae DC3000. Appl. Environ. Microbiol. 78, 5529-5535 (2012).

24. J. L. W. Thudichum, A Treatise on the Chemical Constitution of the Brain, etc (Baillière \& Company, I884).

25. U. Ali, H. Li, X. Wang, L. Guo, Emerging Roles of Sphingolipid Signaling in Plant Response to Biotic and Abiotic Stresses. Mol. Plant. I I, I328-1343 (2018).

26. E. L. Johnson, S. L. Heaver, J. L. Waters, B. I. Kim, A. Bretin, A. L. Goodman, A. T. Gewirtz, T. S. Worgall, R. E. Ley, Sphingolipids produced by gut bacteria enter host metabolic pathways impacting ceramide levels. Nat. Commun. I I, 247I (2020).

27. Y. K. Yeoh, P. G. Dennis, C. Paungfoo-Lonhienne, L. Weber, R. Brackin, M. A. Ragan, S. Schmidt, P. Hugenholtz, Evolutionary conservation of a core root microbiome across plant phyla along a tropical soil chronosequence. Nat. Commun. 8, 215 (2017).

28. F. O. Aylward, B. R. McDonald, S. M. Adams, A. Valenzuela, R. A. Schmidt, L. A. Goodwin, T. Woyke, C. R. Currie, G. Suen, M. Poulsen, Comparison of 26 sphingomonad genomes reveals diverse environmental adaptations and biodegradative capabilities. Appl. Environ. Microbiol. 79, 3724-3733 (2013).

29. S. Asaf, M. Numan, A. L. Khan, A. Al-Harrasi, Sphingomonas: from diversity and genomics to functional role in environmental remediation and plant growth. Crit. Rev. Biotechnol. 40, I38-I52 (2020).

30. A. L. Khan, M. Waqas, S.-M. Kang, A. Al-Harrasi, J. Hussain, A. Al-Rawahi, S. Al-Khiziri, I. Ullah, L. Ali, H.-Y. Jung, I.-J. Lee, Bacterial endophyte Sphingomonas sp. LKII produces gibberellins and IAA and promotes tomato plant growth. J. Microbiol. 52, 689-695 (2014).

3I. C. I. Carlström, C. M. Field, M. Bortfeld-Miller, B. Müller, S. Sunagawa, J. A. Vorholt, Synthetic microbiota reveal priority effects and keystone strains in the Arabidopsis phyllosphere. Nat Ecol Evol. 3, 1445-1454 (2019).

32. N. C. Snelders, H. Rovenich, G. C. Petti, M. Rocafort, J. A. Vorholt, J. R. Mesters, M. F. Seidl, R. Nijland, B. Thomma, A plant pathogen utilizes effector proteins for microbiome manipulation (2020), p. 2020.01.30.926725.

33. G. Innerebner, C. Knief, J. A. Vorholt, Protection of Arabidopsis thaliana against leaf-pathogenic Pseudomonas syringae by Sphingomonas strains in a controlled model system. Appl. Environ. Microbiol. 77, 3202-3210 (20II).

34. J. Regalado, D. S. Lundberg, O. Deusch, S. Kersten, T. Karasov, K. Poersch, G. Shirsekar, D. Weigel, Combining whole genome shotgun sequencing and rDNA amplicon analyses to improve detection of microbe-microbe interaction networks in plant leaves. bioRxiv (2019), p. 823492.

35. S. E. Lindow, M. T. Brandl, Microbiology of the phyllosphere. Appl. Environ. Microbiol. 69, 1875-1883 (2003).

36. C. Vacher, A. Hampe, A. J. Porté, U. Sauer, S. Compant, C. E. Morris, The Phyllosphere: Microbial Jungle at the Plant-Climate Interface. Annu. Rev. Ecol. Evol. Syst. 47, I-24 (2016).

37. D. S. Lundberg, S. Yourstone, P. Mieczkowski, C. D. Jones, J. L. Dangl, Practical innovations for high-throughput amplicon sequencing. Nat. Methods. 10, 999-1002 (2013).

38. C. R. Fitzpatrick, P. Lu-Irving, J. Copeland, D. S. Guttman, P. W. Wang, D. A. Baltrus, K. M. Dlugosch, M. T. J. Johnson, Chloroplast sequence variation and the efficacy of peptide nucleic acids for blocking host amplification in plant microbiome studies. Microbiome. 6, I44 (2018).

39. C. R. Fitzpatrick, J. Copeland, P. W. Wang, D. S. Guttman, P. M. Kotanen, M. T. J. Johnson, Assembly and ecological function of the root microbiome across angiosperm plant species. Proc. Natl. Acad. Sci. U. S. A. II5, EII57-EII65 (20I8).

40. K. Vanbroekhoven, A. Ryngaert, L. Bastiaens, P. Wattiau, M. Vancanneyt, J. Swings, R. De Mot, D. Springael, Streptomycin as a selective agent to facilitate recovery and isolation of introduced and indigenous Sphingomonas from environmental samples. Environ. Microbiol. 6, II 23-I I 36 (2004).

4I. F. A. Simão, R. M. Waterhouse, P. loannidis, E. V. Kriventseva, E. M. Zdobnov, BUSCO: assessing genome assembly and annotation completeness with single-copy orthologs. Bioinformatics. 31, 32।0-32।2 (2015).

42. B. D. Ondov, T. J. Treangen, P. Melsted, A. B. Mallonee, N. H. Bergman, S. Koren, A. M. Phillippy, Mash: fast genome and metagenome distance estimation using MinHash. Genome Biol. I 7, 132 (20I6). 
bioRxiv preprint doi: https://doi.org/10.1101/2021.04.06.438366; this version posted April 13, 2021. The copyright holder for this preprint (which

was not certified by peer review) is the author/funder, who has granted bioRxiv a license to display the preprint in perpetuity. It is made available under aCC-BY 4.0 International license.

Lundberg et al. Contrasting patterns of microbial dominance

43. T. Seemann, Prokka: rapid prokaryotic genome annotation. Bioinformatics. 30, 2068-2069 (2014).

44. W. Ding, F. Baumdicker, R. A. Neher, panX: pan-genome analysis and exploration. Nucleic Acids Res. 46, e5 (20I8).

45. N. A. O'Leary, M. W. Wright, J. R. Brister, S. Ciufo, D. Haddad, R. McVeigh, B. Rajput, B. Robbertse, B. Smith-White, D. Ako-Adjei, A. Astashyn, A. Badretdin, Y. Bao, O. Blinkova, V. Brover, V. Chetvernin, J. Choi, E. Cox, O. Ermolaeva, C. M. Farrell, T. Goldfarb, T. Gupta, D. Haft, E. Hatcher, W. Hlavina, V. S. Joardar, V. K. Kodali, W. Li, D. Maglott, P. Masterson, K. M. McGarvey, M. R. Murphy, K. O’Neill, S. Pujar, S. H. Rangwala, D. Rausch, L. D. Riddick, C. Schoch, A. Shkeda, S. S. Storz, H. Sun, F. Thibaud-Nissen, I. Tolstoy, R. E. Tully, A. R. Vatsan, C. Wallin, D. Webb, W. Wu, M. J. Landrum, A. Kimchi, T. Tatusova, M. DiCuccio, P. Kitts, T. D. Murphy, K. D. Pruitt, Reference sequence (RefSeq) database at NCBI: current status, taxonomic expansion, and functional annotation. Nucleic Acids Res. 44, D733-45 (2016).

46. C. Camacho, G. Coulouris, V. Avagyan, N. Ma, J. Papadopoulos, K. Bealer, T. L. Madden, BLAST+: architecture and applications. BMC Bioinformatics. I0, 42 I (2009).

47. N. Atamna-lsmaeel, O. Finkel, F. Glaser, C. von Mering, J. A. Vorholt, M. Kobližek, S. Belkin, O. Béjà, Bacterial anoxygenic photosynthesis on plant leaf surfaces. Environ. Microbiol. Rep. 4, 209-216 (2012).

48. S. Siddaramappa, V. Viswanathan, S. Thiyagarajan, A. Narjala, Genomewide characterisation of the genetic diversity of carotenogenesis in bacteria of the order Sphingomonadales. Microb Genom. 4 (2018), doi: 10.1099/mgen.0.000172.

49. S. Hanada, Anoxygenic Photosynthesis -A Photochemical Reaction That Does Not Contribute to Oxygen Reproduction. Microbes Environ. 3 I, I-3 (2016).

50. O. M. Finkel, T. O. Delmont, A. F. Post, S. Belkin, Metagenomic Signatures of Bacterial Adaptation to Life in the Phyllosphere of a Salt-Secreting Desert Tree. Appl. Environ. Microbiol. 82, 2854-286I (2016).

5I. S. J. Unterholzner, B. Poppenberger, W. Rozhon, Toxin-antitoxin systems: Biology, identification, and application. Mob. Genet. Elements. 3, e26219 (2013).

52. H. Li, Minimap2: pairwise alignment for nucleotide sequences. Bioinformatics. 34, 3094-3100 (20I8).

53. C. Vogel, N. Bodenhausen, W. Gruissem, J. A. Vorholt, The Arabidopsis leaf transcriptome reveals distinct but also overlapping responses to colonization by phyllosphere commensals and pathogen infection with impact on plant health. New Phytol. 21 2, 192-207 (2016).

54. B. Laflamme, M. M. Dillon, A. Martel, R. N. D. Almeida, D. Desveaux, D. S. Guttman, The pan-genome effector-triggered immunity landscape of a host-pathogen interaction. Science. 367, 763-768 (2020).

55. X.-F. Xin, K. Nomura, K. Aung, A. C. Velásquez, J. Yao, F. Boutrot, J. H. Chang, C. Zipfel, S. Y. He, Bacteria establish an aqueous living space in plants crucial for virulence. Nature. 539, 524-529 (2016).

56. R. N. Pruitt, L. Zhang, S. C. Saile, D. Karelina, K. Fröhlich, W.-L. Wan, S. Rao, A. A. Gust, F. Locci, Matthieu H A, Bart P H, J.-M. Zhou, J. L. Dangl, D. Weigel, J. E. Parker, F. El Kasmi, T. Nürnberger, Arabidopsis cell surface LRR immune receptor signaling through the EDSI-PAD4-ADRI node. Cold Spring Harbor Laboratory (2020), p. 2020.11.23.391516.

57. H. Cui, E. Gobbato, B. Kracher, J. Qiu, J. Bautor, J. E. Parker, A core function of EDSI with PAD4 is to protect the salicylic acid defense sector in Arabidopsis immunity. New Phytol. 213, I802-1817 (2017).

58. D. D. Bhandari, D. Lapin, B. Kracher, P. von Born, J. Bautor, K. Niefind, J. E. Parker, An EDSI heterodimer signalling surface enforces timely reprogramming of immunity genes in Arabidopsis. Nat. Commun. 10, 772 (2019).

59. K. Jakob, J. M. Kniskern, J. Bergelson, The role of pectate lyase and the jasmonic acid defense response in Pseudomonas viridiflava virulence. Mol. Plant. Microbe. Interact. 20, I46-I58 (2007).

60. D. S. Lundberg, P. Pramoj Na Ayutthaya, A. Strauß, G. Shirsekar, W.-S. Lo, T. Lahaye, D. Weigel, Host-associated microbe PCR (hamPCR): accessing new biology through convenient measurement of both microbial load and community composition. bioRxiv, I0.1 I0I/2020.05.19.103937 (2020).

6I. F. J. Whelan, B. Waddell, S. A. Syed, S. Shekarriz, H. R. Rabin, M. D. Parkins, M. G. Surette, Culture-enriched metagenomic sequencing enables in-depth profiling of the cystic fibrosis lung microbiota. Nat Microbiol. 5, 379-390 (2020).

62. Y. Bai, D. B. Müller, G. Srinivas, R. Garrido-Oter, E. Potthoff, M. Rott, N. Dombrowski, P. C. Münch, S. Spaepen, M. Remus-Emsermann, B. Hüttel, A. C. McHardy, J. A. Vorholt, P. Schulze-Lefert, Functional overlap of the Arabidopsis leaf and root microbiota. Nature. 528, 364-369 (2015).

63. M. Ayliffe, C. K. Sørensen, Plant nonhost resistance: paradigms and new environments. Curr. Opin. Plant Biol. 50, 104-113 (2019). 
bioRxiv preprint doi: https://doi.org/10.1101/2021.04.06.438366; this version posted April 13, 2021. The copyright holder for this preprint (which

was not certified by peer review) is the author/funder, who has granted bioRxiv a license to display the preprint in perpetuity. It is made available under aCC-BY 4.0 International license.

64. R. Panstruga, M. J. Moscou, What is the Molecular Basis of Nonhost Resistance? Mol. Plant. Microbe. Interact. 33, $1253-1264$ (2020).

65. R. Cai, J. Lewis, S. Yan, H. Liu, C. R. Clarke, F. Campanile, N. F. Almeida, D. J. Studholme, M. Lindeberg, D. Schneider, M. Zaccardelli, J. C. Setubal, N. P. Morales-Lizcano, A. Bernal, G. Coaker, C. Baker, C. L. Bender, S. Leman, B. A. Vinatzer, The plant pathogen Pseudomonas syringae pv. tomato is genetically monomorphic and under strong selection to evade tomato immunity. PLoS Pathog. 7, el 002130 (201I).

66. K. Yoshida, V. J. Schuenemann, L. M. Cano, M. Pais, B. Mishra, R. Sharma, C. Lanz, F. N. Martin, S. Kamoun, J. Krause, M. Thines, D. Weigel, H. A. Burbano, The rise and fall of the Phytophthora infestans lineage that triggered the Irish potato famine. Elife. 2, e0073I (2013).

67. N. Rohland, D. Reich, Cost-effective, high-throughput DNA sequencing libraries for multiplexed target capture. Genome Res. 22, 939-946 (2012).

68. N. Caruccio, Preparation of next-generation sequencing libraries using Nextera ${ }^{\mathrm{TM}}$ technology: simultaneous DNA fragmentation and adaptor tagging by in vitro transposition. Methods Mol. Biol. 733, 24I-255 (20II).

69. A. Bankevich, S. Nurk, D. Antipov, A. A. Gurevich, M. Dvorkin, A. S. Kulikov, V. M. Lesin, S. I. Nikolenko, S. Pham, A. D. Prjibelski, A. V. Pyshkin, A. V. Sirotkin, N. Vyahhi, G. Tesler, M. A. Alekseyev, P. A. Pevzner, SPAdes: a new genome assembly algorithm and its applications to single-cell sequencing. J. Comput. Biol. 19, 455-477 (20I2).

70. B. J. Walker, T. Abeel, T. Shea, M. Priest, A. Abouelliel, S. Sakthikumar, C. A. Cuomo, Q. Zeng, J. Wortman, S. K. Young, A. M. Earl, Pilon: an integrated tool for comprehensive microbial variant detection and genome assembly improvement. PLoS One. 9, el I 2963 (2014).

7I. H. den Bakker, hcdenbakker - Overview (Github; https://github.com/hcdenbakker).

72. S. Koren, A. M. Phillippy, One chromosome, one contig: complete microbial genomes from long-read sequencing and assembly. Curr. Opin. Microbiol. 23, II 0-120 (20I5).

73. R. R. Wick, L. M. Judd, K. E. Holt, Performance of neural network basecalling tools for Oxford Nanopore sequencing. Genome Biol. 20, 129 (2019).

74. H. Li, Minimap and miniasm: fast mapping and de novo assembly for noisy long sequences. Bioinformatics. 32 , 2103-2110 (2016).

75. H. Li, Aligning sequence reads, clone sequences and assembly contigs with BWA-MEM. arXiv [q-bio.GN] (2013), (available at http://arxiv.org/abs/I303.3997).

76. B. Buchfink, C. Xie, D. H. Huson, Fast and sensitive protein alignment using DIAMOND. Nat. Methods. I 2, 59-60 (2015).

77. H. Jiang, R. Lei, S.-W. Ding, S. Zhu, Skewer: a fast and accurate adapter trimmer for next-generation sequencing paired-end reads. BMC Bioinformatics. 15, 182 (2014).

78. H. Li, B. Handsaker, A. Wysoker, T. Fennell, J. Ruan, N. Homer, G. Marth, G. Abecasis, R. Durbin, 1000 Genome Project Data Processing Subgroup, The Sequence Alignment/Map format and SAMtools. Bioinformatics. 25, 2078-2079 (2009).

79. C. Jain, L. M. Rodriguez-R, A. M. Phillippy, K. T. Konstantinidis, S. Aluru, High throughput ANI analysis of $90 \mathrm{~K}$ prokaryotic genomes reveals clear species boundaries. Nat. Commun. 9, 5 II 4 (20I8).

80. G. R. Warnes, B. Bolker, L. Bonebakker, R. Gentleman, W. Huber, A. Liaw, T. Lumley, M. Maechler, A. Magnusson, S. Moeller, M. Schwartz, B. Venables, gplots: Various R Programming Tools for Plotting Data (2020), (available at https://CRAN.R-project.org/package=gplots).

8I. C. A. Barragan, R. Wu, S.-T. Kim, W. Xi, A. Habring, J. Hagmann, A.-L. Van de Weyer, M. Zaidem, W. W. H. Ho, G. Wang, I. Bezrukov, D. Weigel, E. Chae, RPW8/HR repeats control NLR activation in Arabidopsis thaliana. PLoS Genet. 15, el 008313 (2019). 